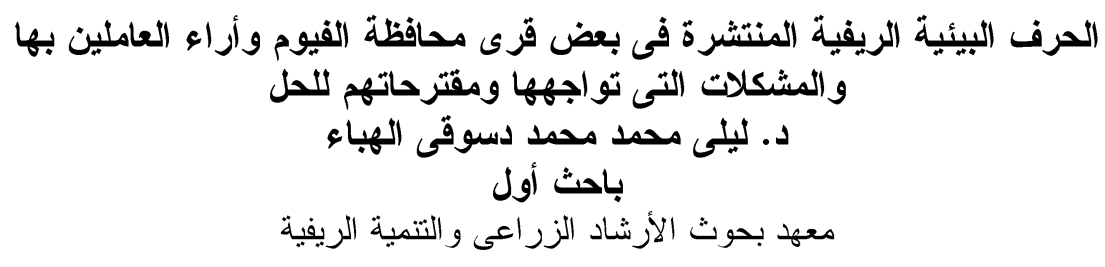

إستهذف البحث بصفة أساسية التعرف على المعلومات الخاصة بالحرف البيئية الريفية بمنطقة

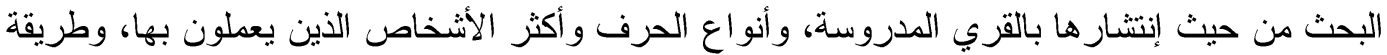

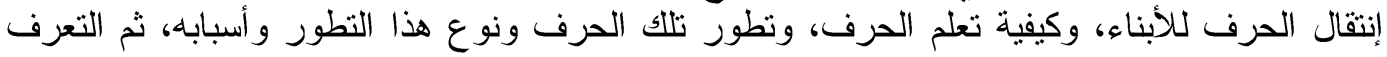

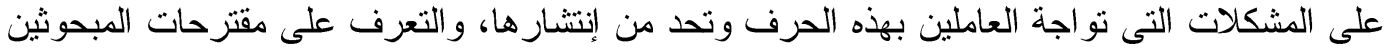
للتغلب على هذه المشكلات، والدور الذى يمكن أن يساهم بة الإرشاد الزراعى فئ مجال تتمية وتطوير

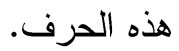

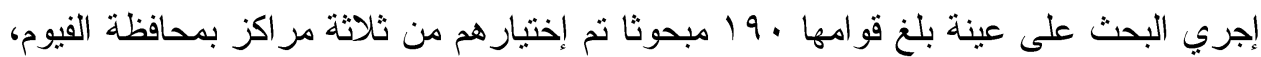

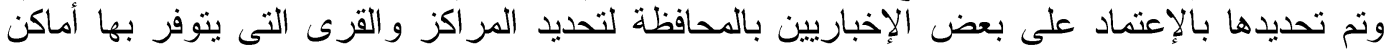

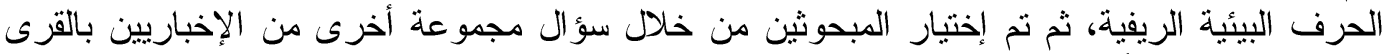

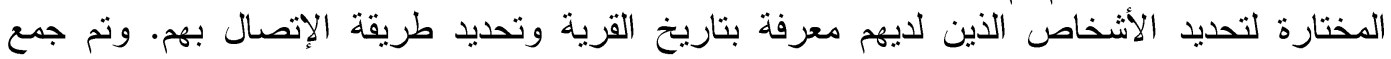

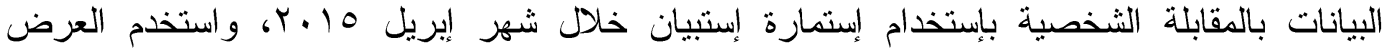
الجدولي لعرض النتائج، و التعبير عن الإستجابات بطريقة وصفية باستخدام التكرارات والتئ والنسب المئوية.

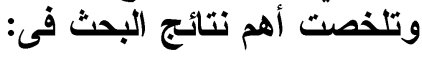

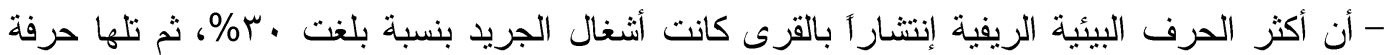

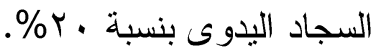

- إحتلت طريقة إنتقال الحرف من الآباء إلى الأبناء المرتبة الأولى فى تعلم الأبناء الحرف فى الصغ الصغر

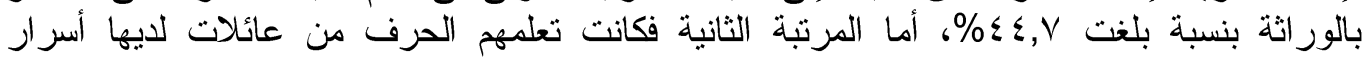

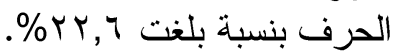

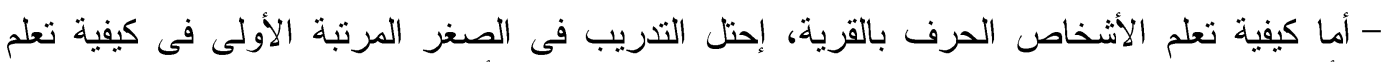

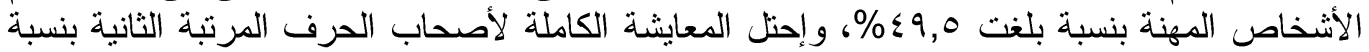

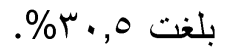

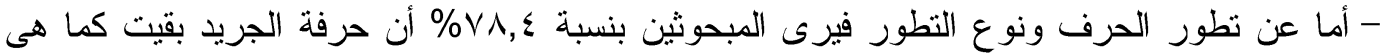

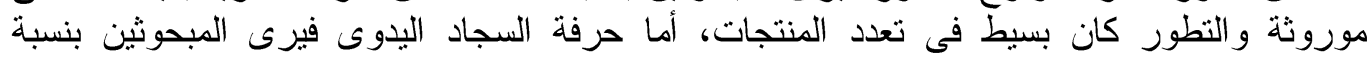

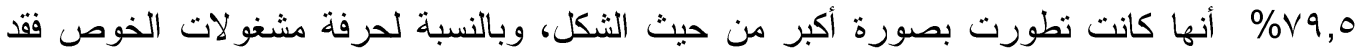

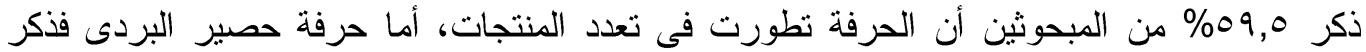

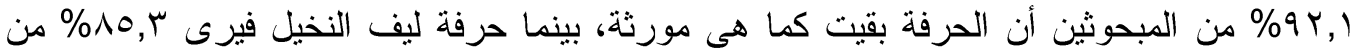
المبحوثين أن الحرفة بقيث كما هي موروثة النة

Fayoum J. Agric. Res. \& Dev., Vol. 31, No.1, January, 2017 
- وكثفت الدراسة أن أكثر المشكلات التى تقلل من إنتقال الحرف من الآباء إلى الآبناء: أن العائد

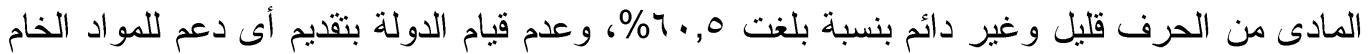

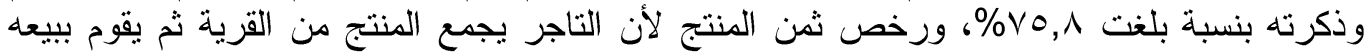

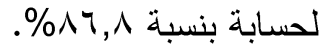

- وكانت أهم مقترحات المبحوثين للتغلب على المشكلات: عمل تأمين صحى لأصحاب الحرف بنسبة

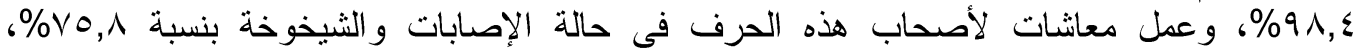

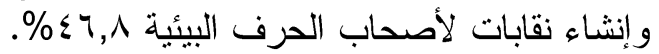

- أن أكثر من نصف المبحوثين بنسبة ه, •0\% على أن يساعد الإزشاد الزراعى فى مجال تتشيط الحرف البيئية الريفية. مقدمة البحث

لاشك أن الحرف التقليدية هى نتاج حضاري من التفاعل الحي بين المجتمعات المحلية بما

تحمله من رؤى وقيم حضارية بين بيئتها الطبيعية وبين المجتمعات الأخرى منذ آلآن الاف السنين، أى أنها

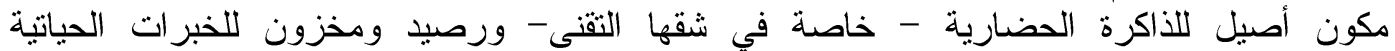

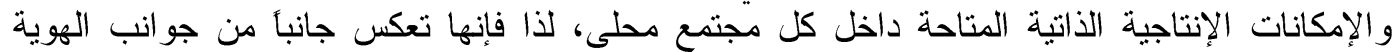

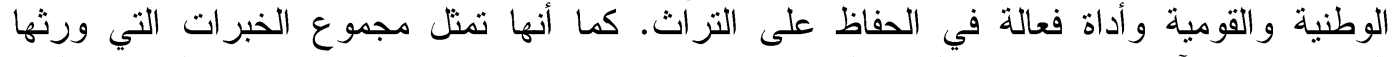

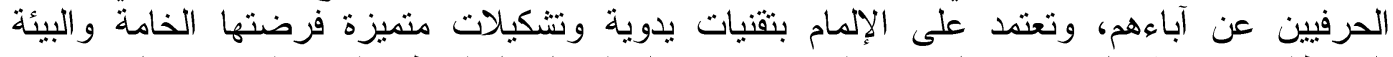

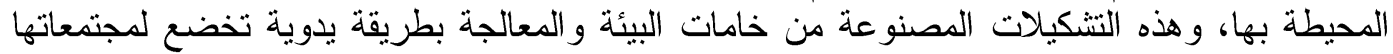

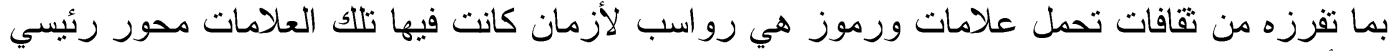

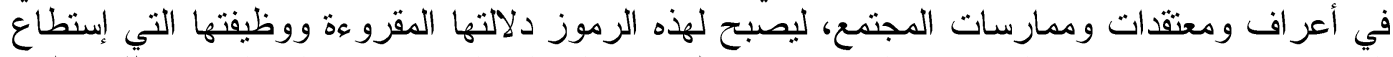

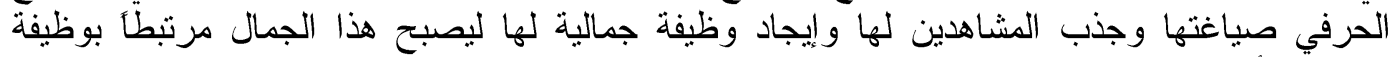

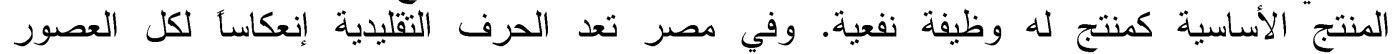

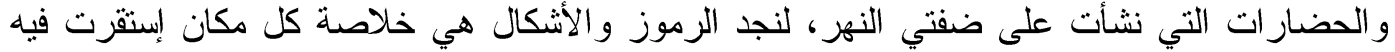

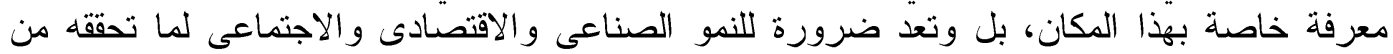

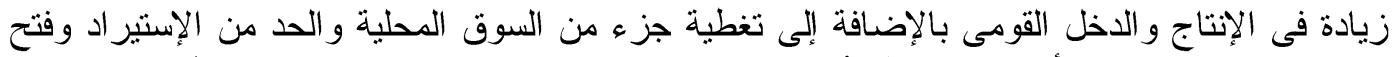

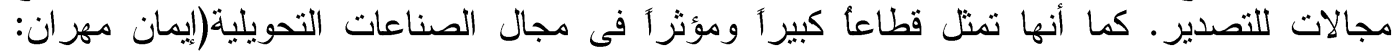

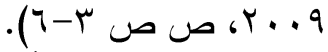

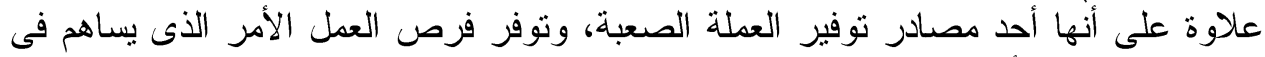

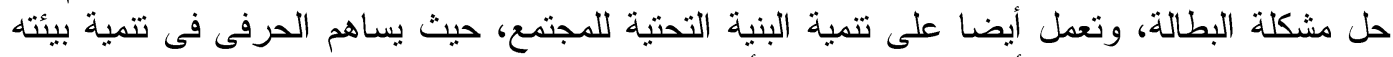

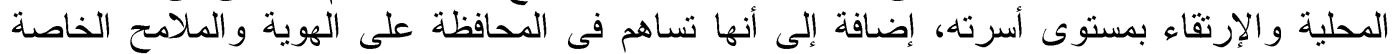

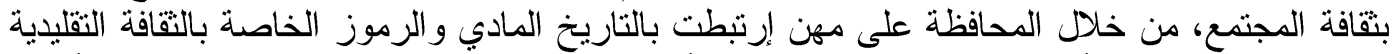

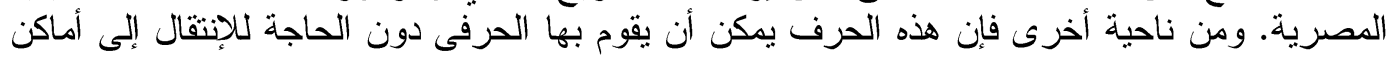

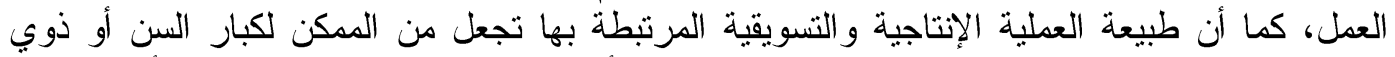

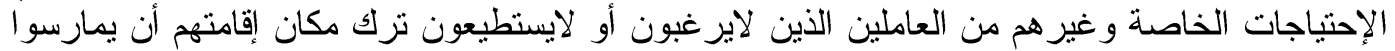

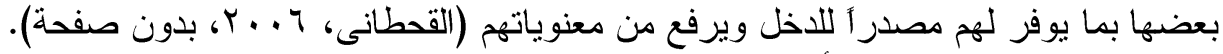

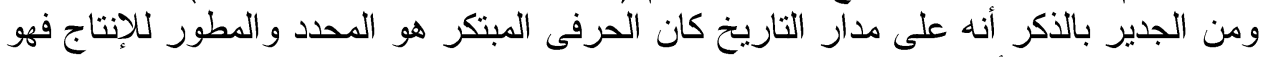

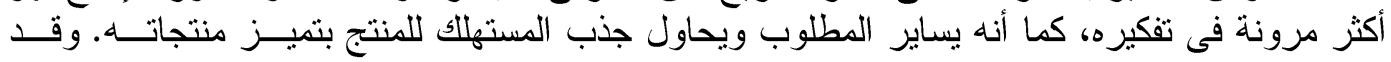

Fayoum J. Agric. Res. \& Dev., Vol. 31, No.1, January, 2017 


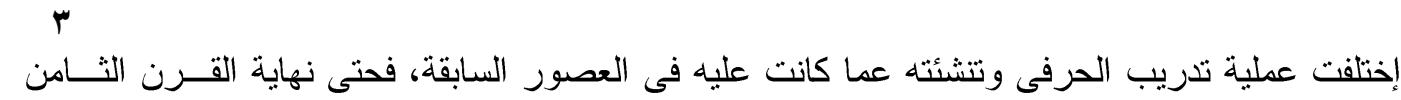

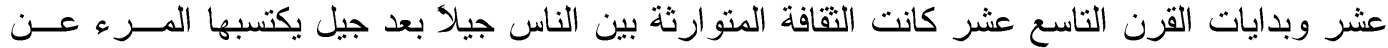

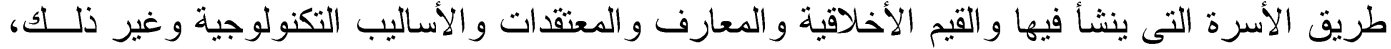

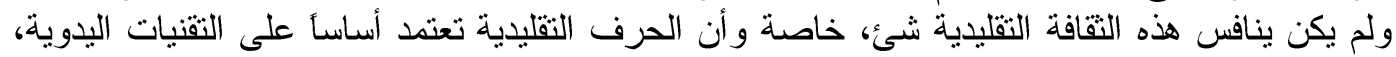

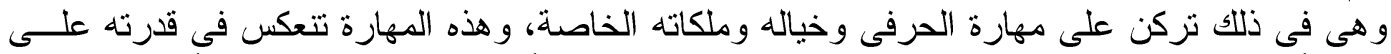

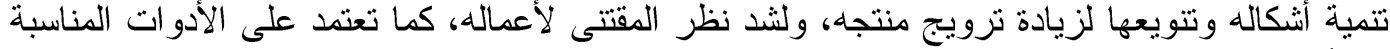

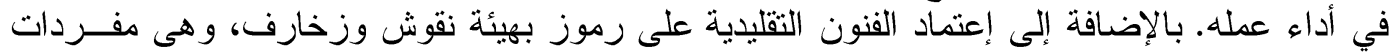

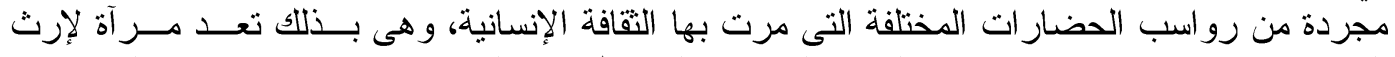

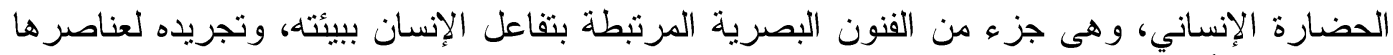

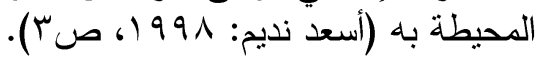

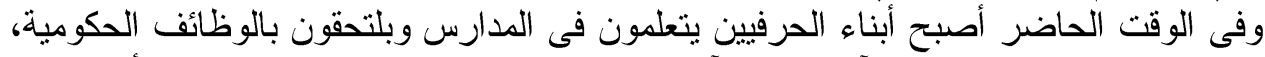

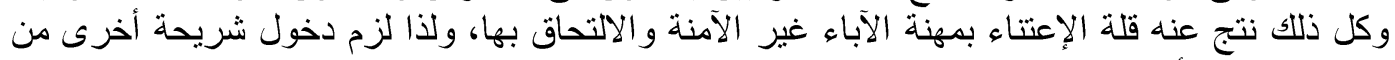

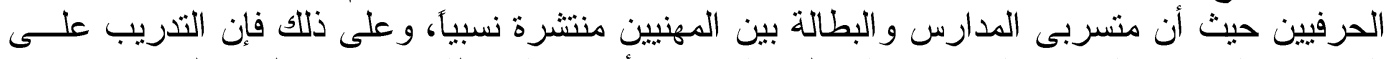

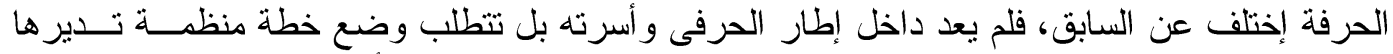

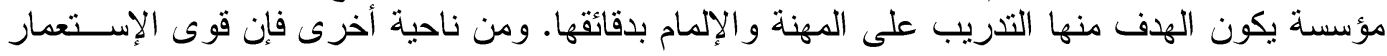

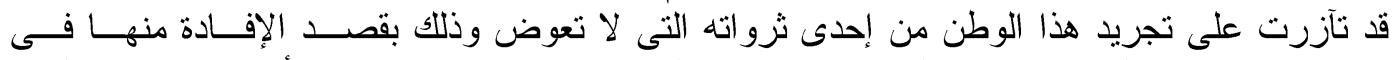

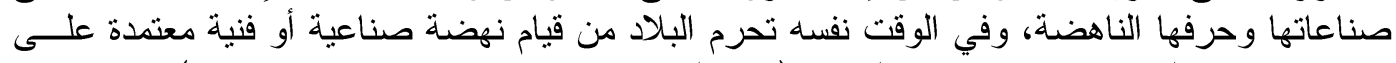

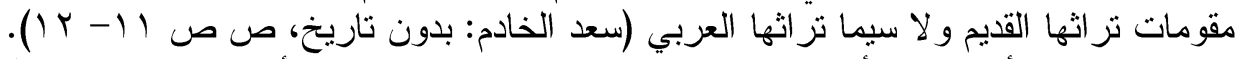

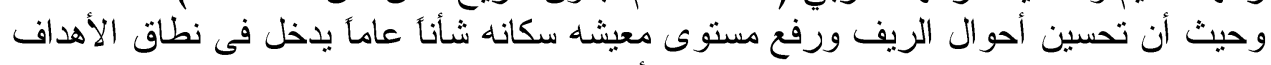

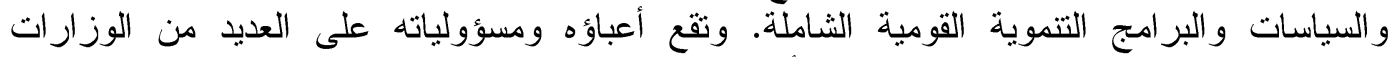

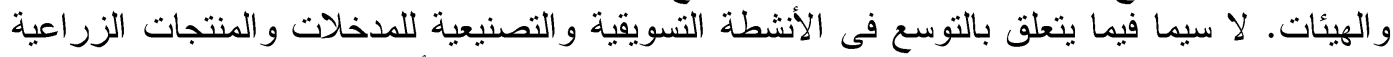

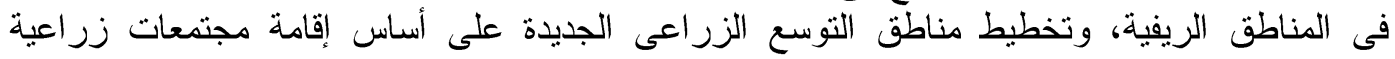

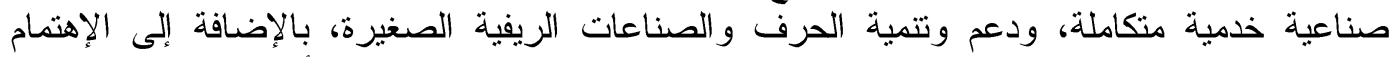

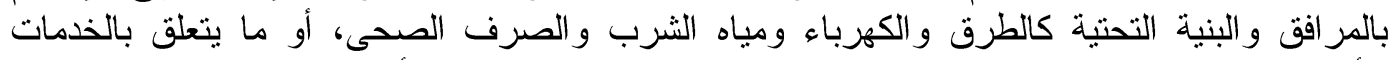

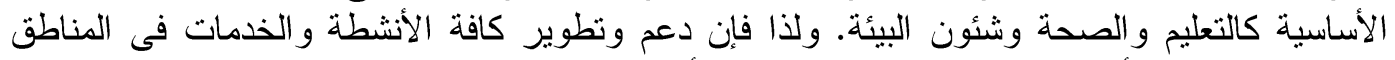

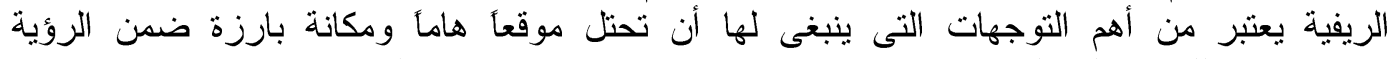

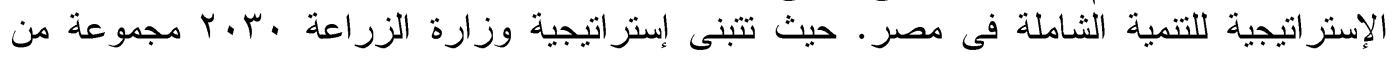

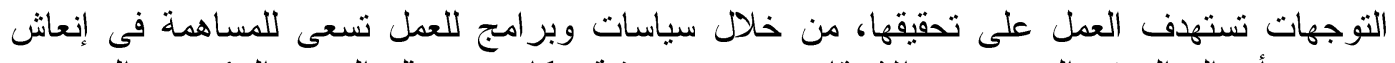

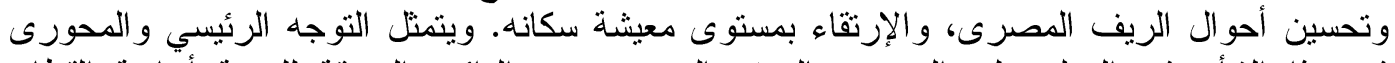

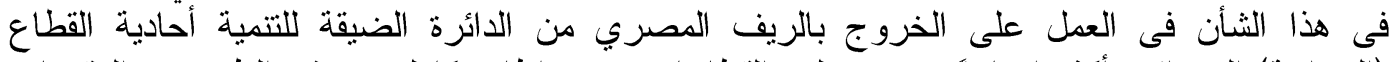

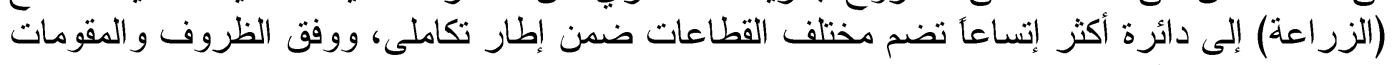

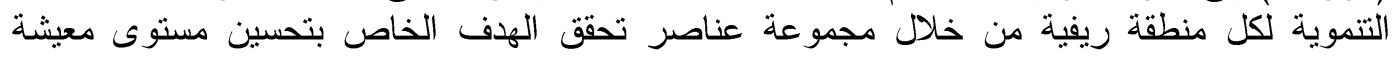

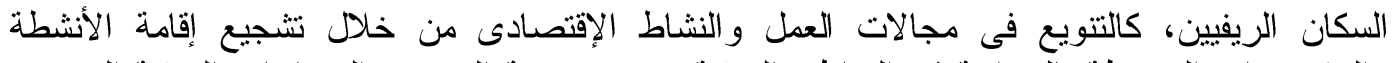

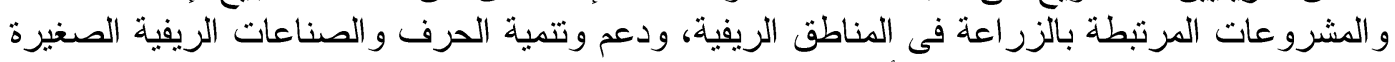

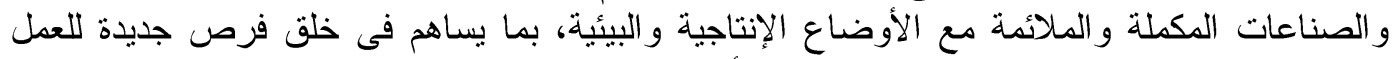

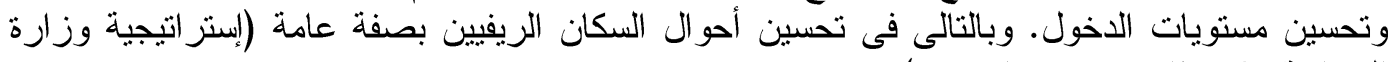

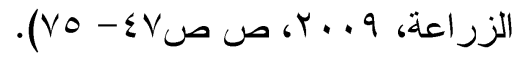

Fayoum J. Agric. Res. \& Dev., Vol. 31, No.1, January, 2017 
ويعتبر الإرشاد الزراعي أحد أهم المؤسسات التعليمية غير الرسمية المعنية بتعليم الأفراد كيفية حل

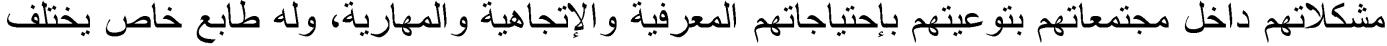

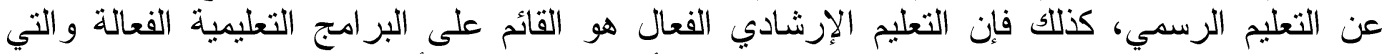

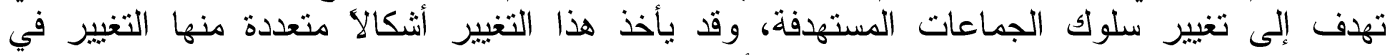
المعارف و الإتجاهات و المهارات. ولذلك يجب أن أن تكون الخدمات التعليمية الإزشادية مستندة إلى نتائج

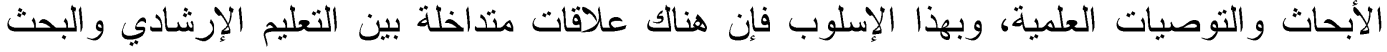

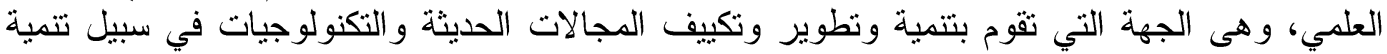

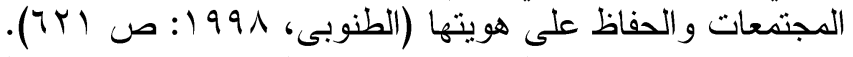

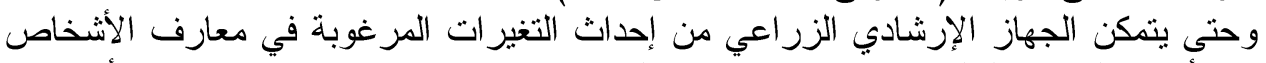

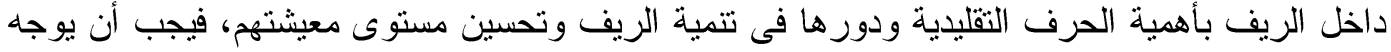

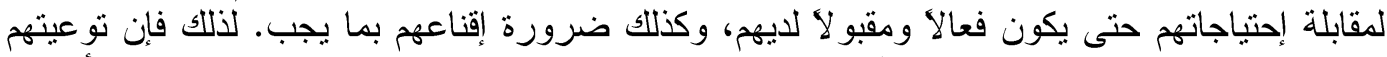

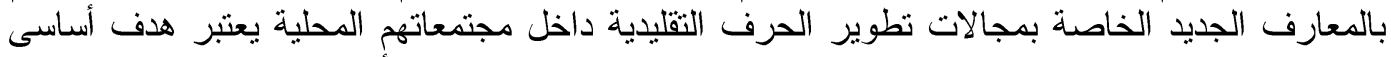

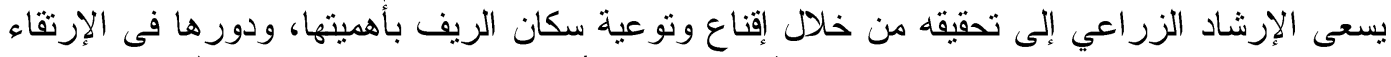

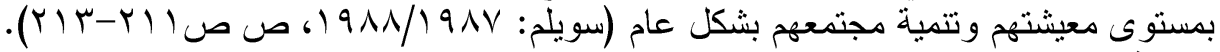

مشكلة البحث ميثن

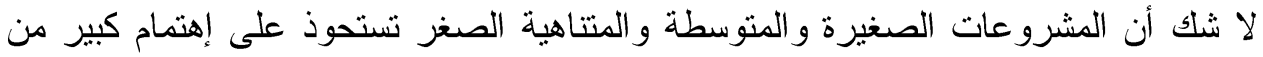

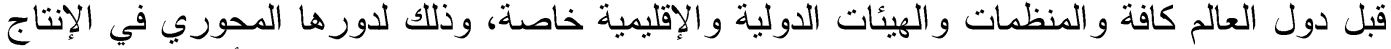

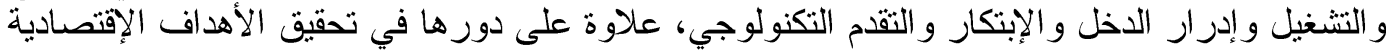

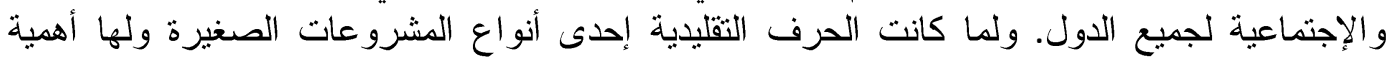

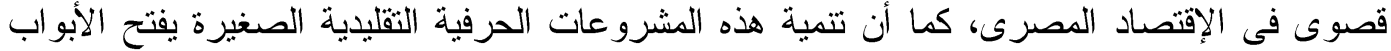

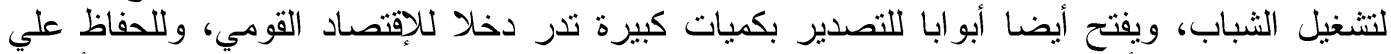

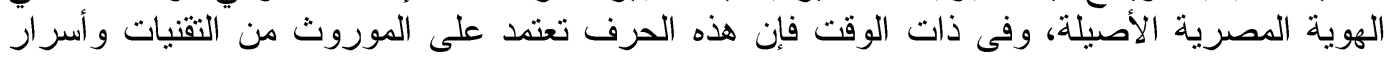

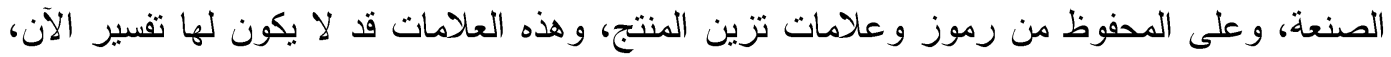

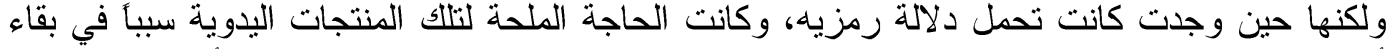

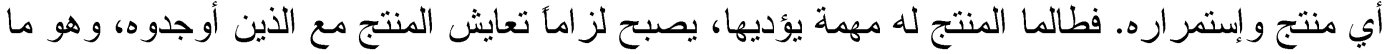
يؤدى لتطوره وسط منظو إنظوه فئه المجتمعية.

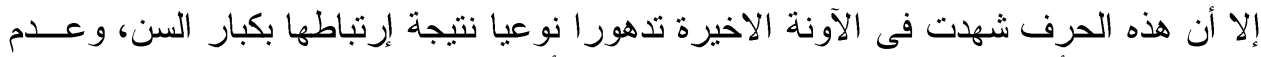

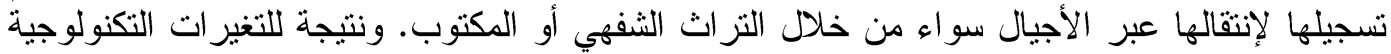

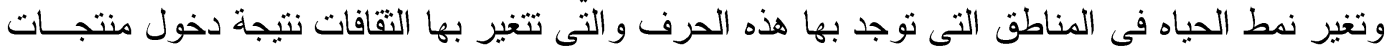

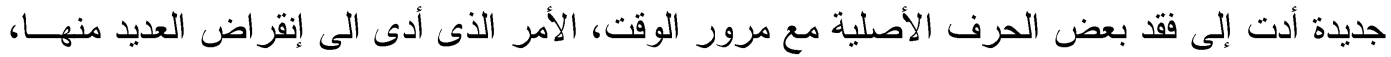

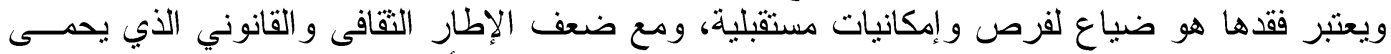

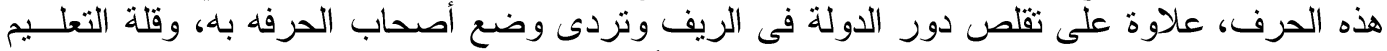

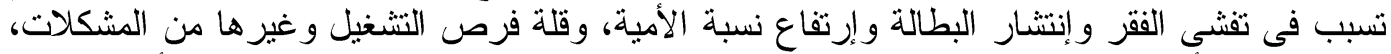

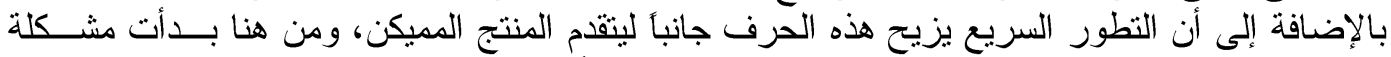

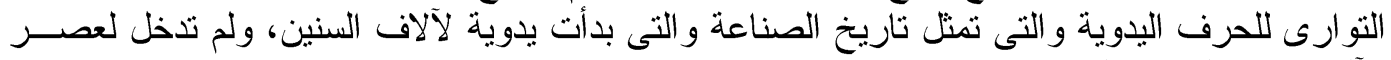
الآلة إلا فى العصر الحديث.

Fayoum J. Agric. Res. \& Dev., Vol. 31, No.1, January, 2017 


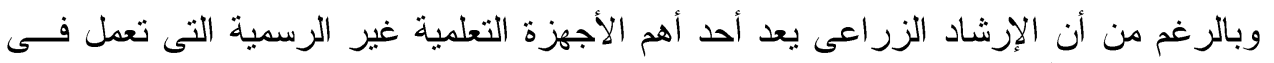

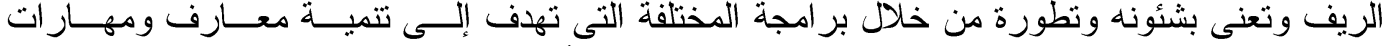
و إتجاهات السكان الريفيين فى مختلف نواحى الحياه بإعتبار أن نتمية المجتمع المحلى الريفى، والإسهام

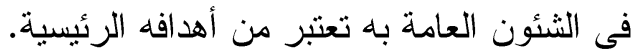

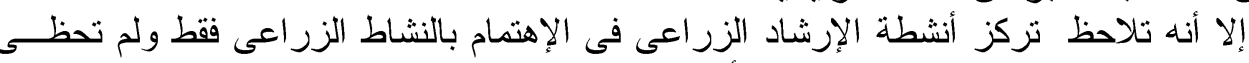

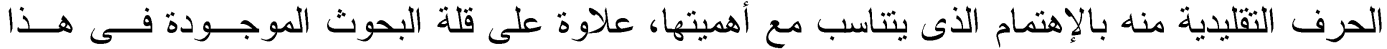

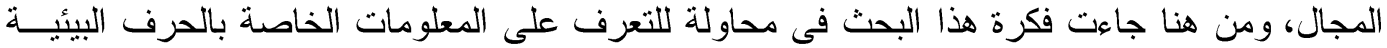

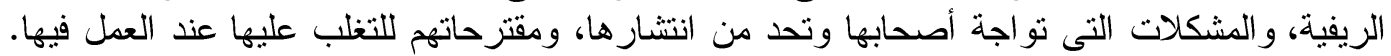

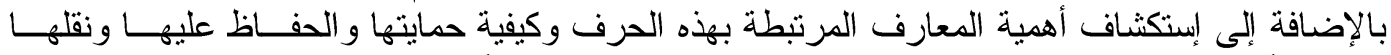

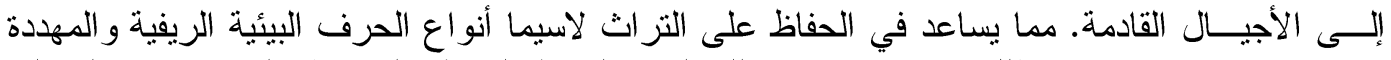

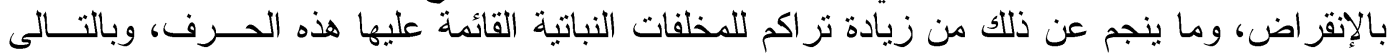

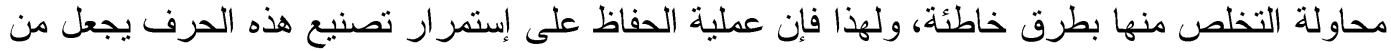
الضرورى تسجيلها وتوثيقها حتى تصبح فى متتاول وكلاء التغيير و المنظمات و الهيئات الدوليه للإستفادهاد منها في تطوير وتتمية المجتمعات المحلية.

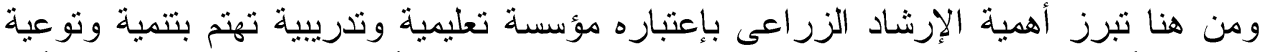

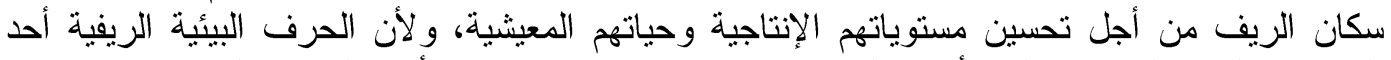

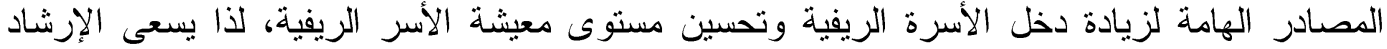

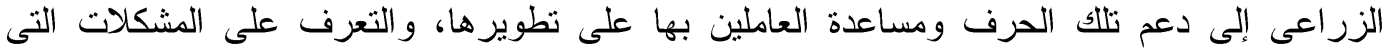

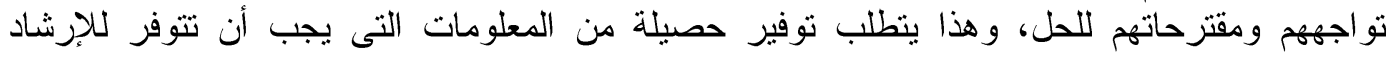

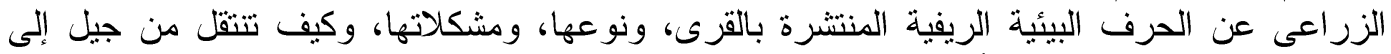

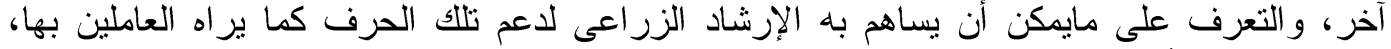

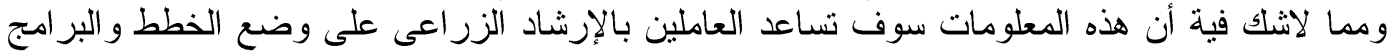

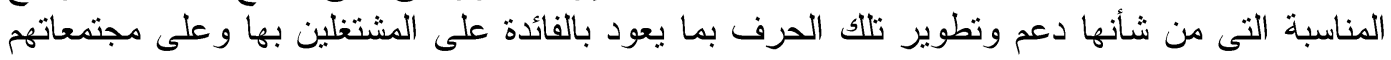

تكمن أهمية البحث في أن نتائجه تلقى الضوء على الحرف البيئية الريفية المنتشرة فى قرى الهى الهى

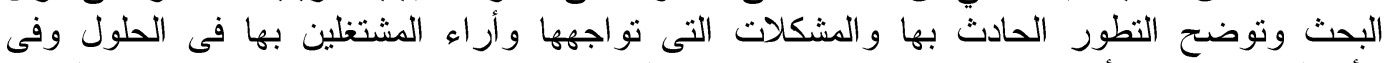

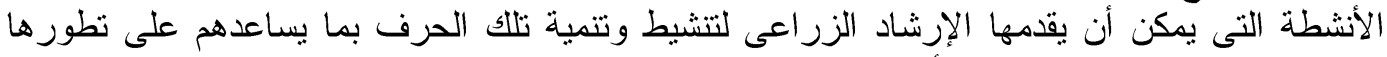

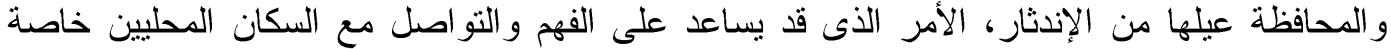

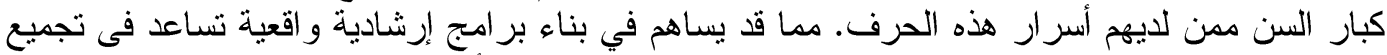

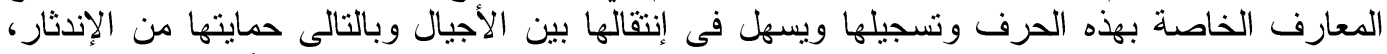

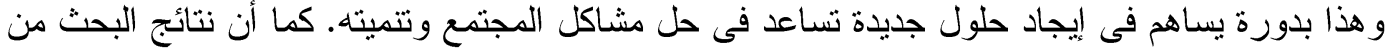

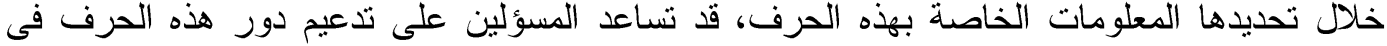

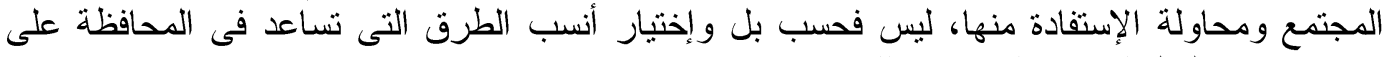

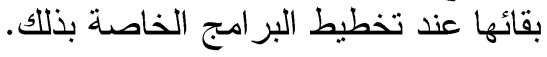

Fayoum J. Agric. Res. \& Dev., Vol. 31, No.1, January, 2017 
أهداف البحث على المعلومات الخاصة بالحرف البيئية الريفية بمنطقة البحث من حيث:

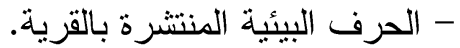
- أنو اع الحرف و أكثر الأشخاص الذائة الذين يعملون بها.

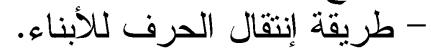

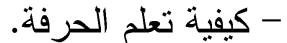

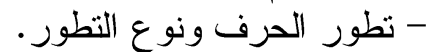

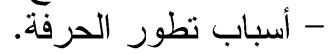

r. التعرف على المشكلات التى تواجة العاملين بالحرف البيئية الريفية وتحد من إتثشارها بمنطقة البحث من حيث: - المشكلات المتعلقة بنو ارث الحرفة.

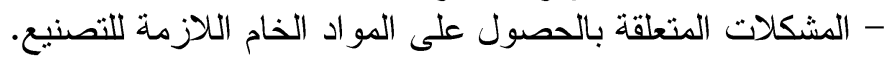

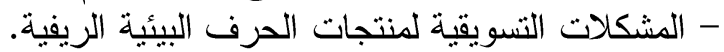

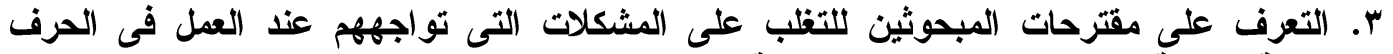

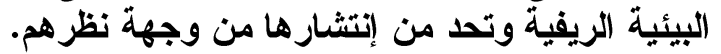

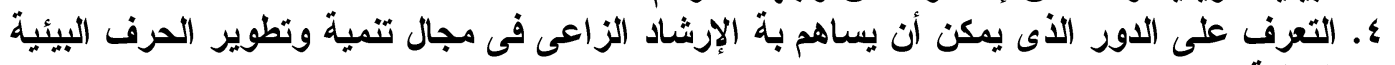
الريفية. هـ إقتر اح خطة عمل لبرنامج تدريبى لتأهيل شباب القرى للعمل فى الحرف البيئية الريفية. الطريقة البحثية إنشتملت الطريقة البحثية على التعاريف الإجرائية، ومجالات البحث، وأسلوب جمع البيانات،

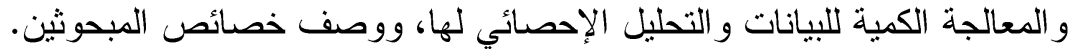

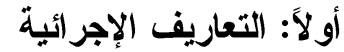
الحرف البيئية الريفية: يقصد بهائة الإجة في هذا البحث جميع الحرف التقليدية القائمة فى صناعتها على خامات نباتية أو حيو انية أو أب خامية البهات متوفرة بالبيئة الريفية.

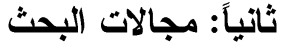

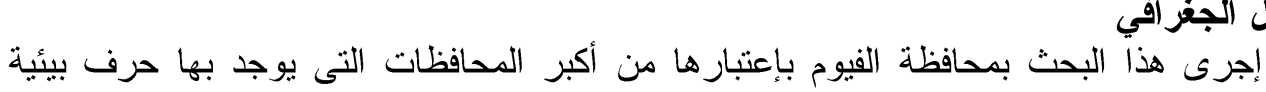

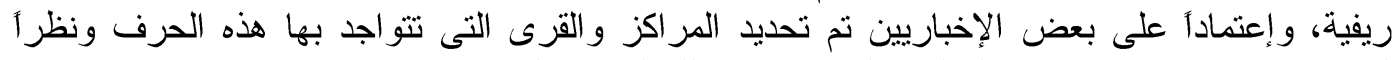

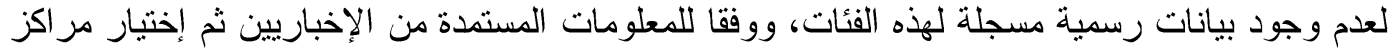

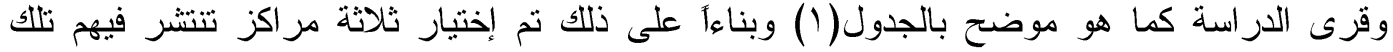

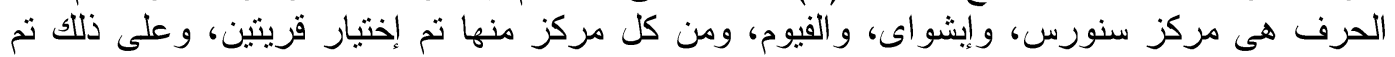

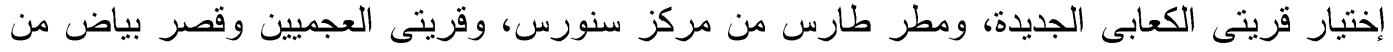
مركز إبشو ای، وقريتى ديسا، والإعلام من مركز الفيوم.

Fayoum J. Agric. Res. \& Dev., Vol. 31, No.1, January, 2017 
جدول (1): توزيع العينة على المر اكز والقزى المدروسة بمحافظة الفيوم

\begin{tabular}{|c|c|c|}
\hline عدد المبحوثين & القرى & المر اكز \\
\hline$\varepsilon r$ & الكعابى الجديدة & \multirow{2}{*}{ سنورس } \\
\hline rI & مطر طارس & \\
\hline$V r$ & & إجمالى المركز \\
\hline ry & قصر بياض & \multirow{2}{*}{ إبشواى } \\
\hline$r \wedge$ & العجميين & \\
\hline $7 \varepsilon$ & \multicolumn{2}{|r|}{ إجمالى المركز } \\
\hline ro & دسيا & \multirow[b]{2}{*}{ الفيوم } \\
\hline$r \wedge$ & الإعلام & \\
\hline or & \multicolumn{2}{|r|}{ إجمالى المركز } \\
\hline 19. & & الإجمالى العام \\
\hline
\end{tabular}

و لإختيار أفراد عينة البحث إعتمد على نفس المعيار السابق بالإعتماد على الإخباريين بالقرى

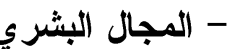

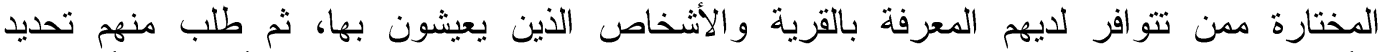

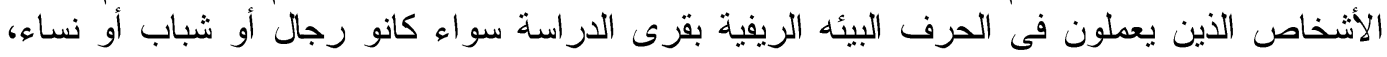

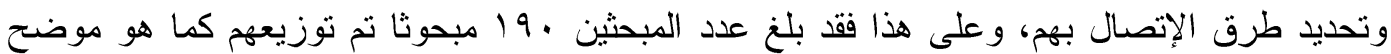

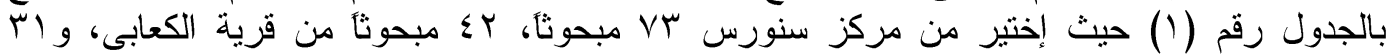

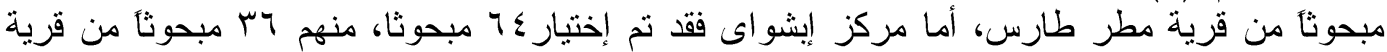

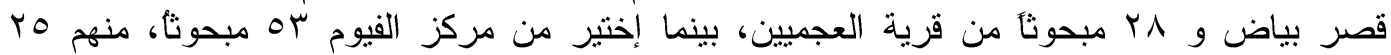

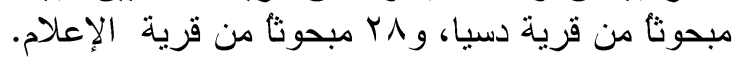

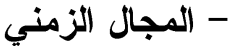

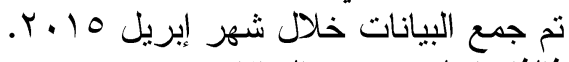
ثالثا: إسلوب جمع البيانات خلات اليات تم جمع البيانات بالمقابلة الشخصية مع المبحوثين بإستخدام إستمارة إستبيان، وقد تضدنت

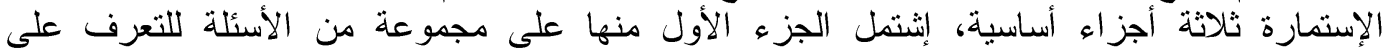

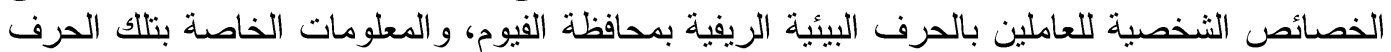

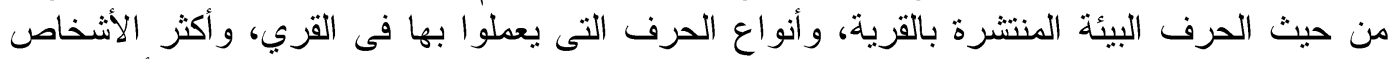

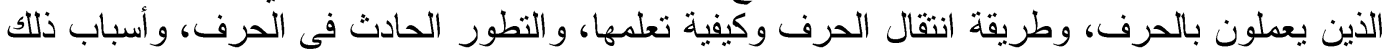

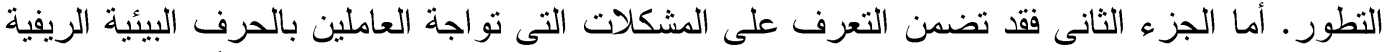

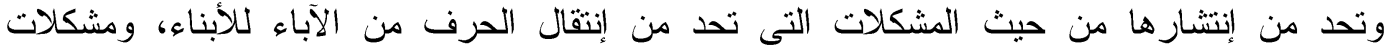

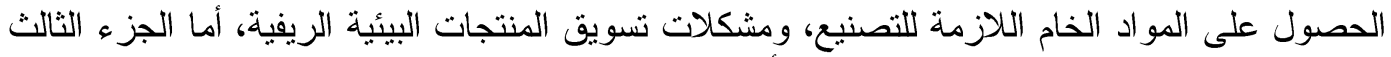

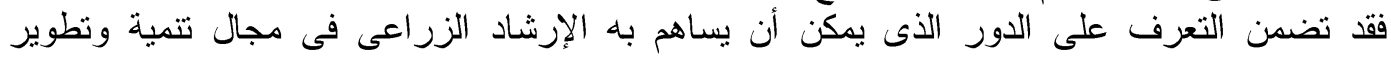

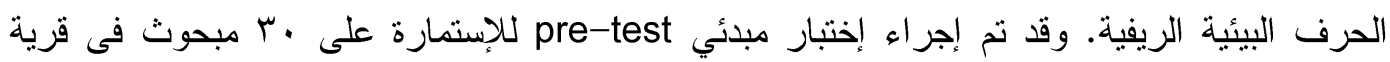
الناصرية بمركز الفيوم بمحافظة الفيوم، وبعد إجراء التعديلات اللازمة للإستمارة و التأكد من صلاحيتها

Fayoum J. Agric. Res. \& Dev., Vol. 31, No.1, January, 2017 
$\wedge$

تم صياغتها فى شكلها النهائي واستخدمها فى جمع البيانات، ثم تفريغها وجدولتها تمهيدا لتحليلها وعرضها. رابعا: قياس المتغيرات البحثية و المعالجة الكمية للبيانات

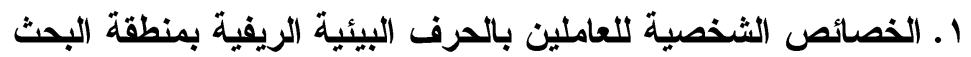

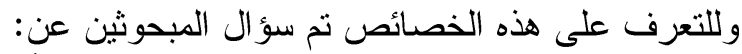

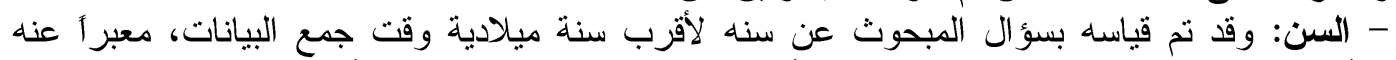

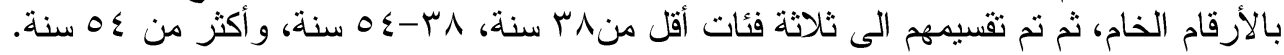

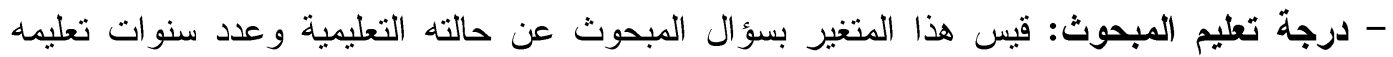

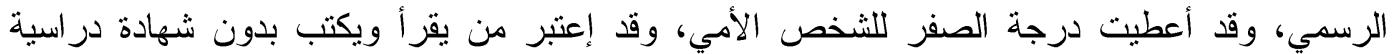

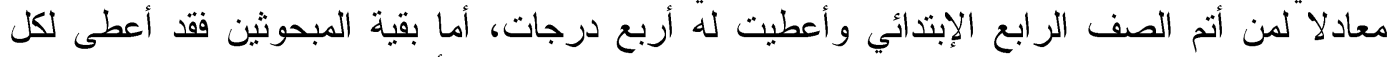

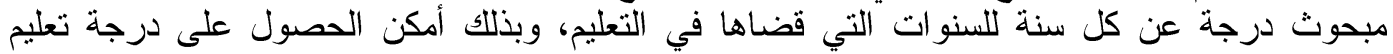
المبحوث. - المهنه: قيس هذا المتغير بسؤال المبحوث عن المهنه التى يعمل بها، هل هى الحرفة فقط، أم هناك مهنة أخرى بجانبها.

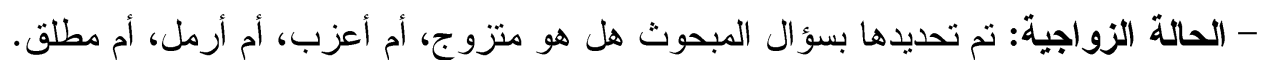

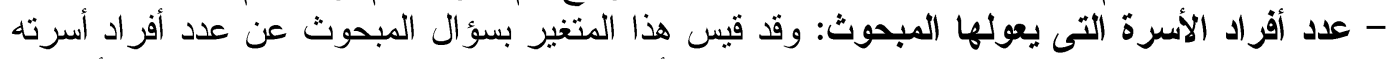

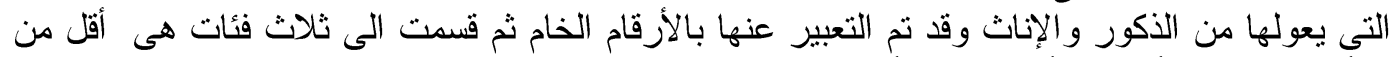

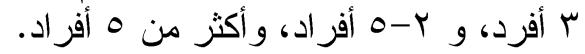

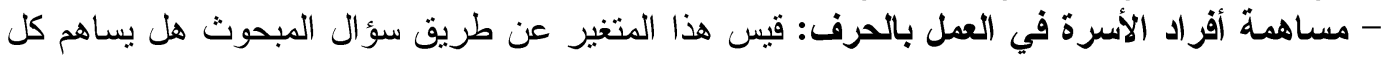

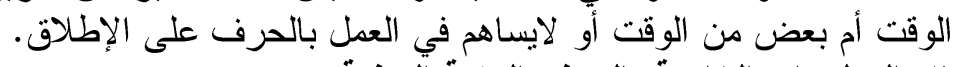

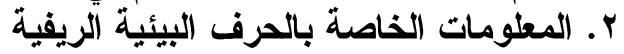

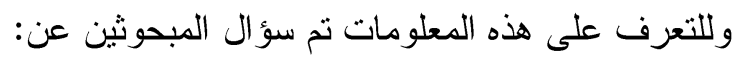
أ. الحرف البيئة الريفية المنتشرة بالقرية: وتعنى الحرف البيئية الريفية المنتشرة بالقرية التى يعمل بها المبحوثين كمهنة رئيسية.

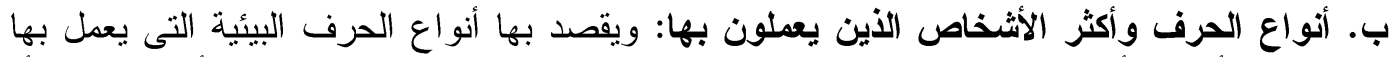

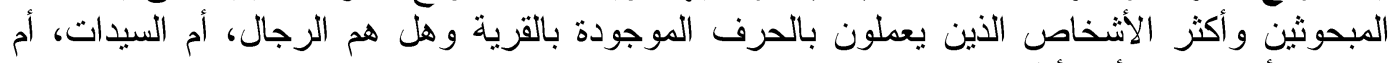

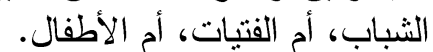

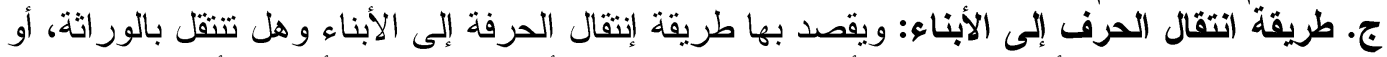

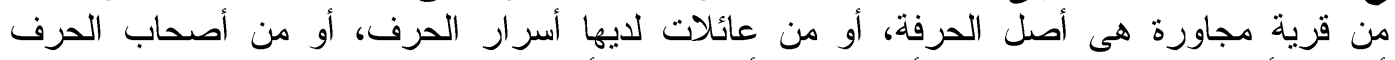

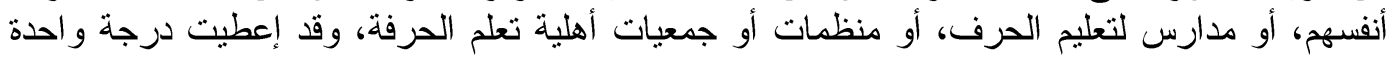

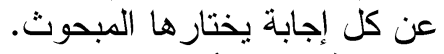

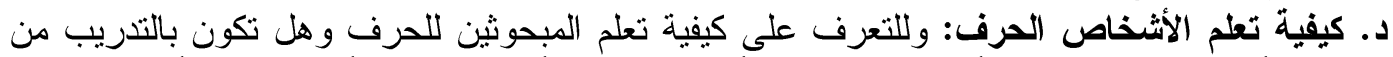

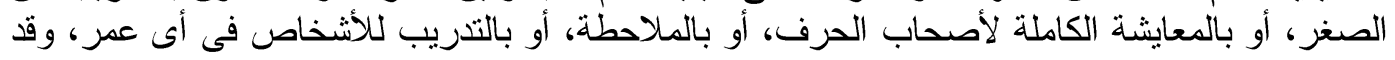
اعطى المبحوث درجة والمعة وائة عن كل إحابة يختار ها.

Fayoum J. Agric. Res. \& Dev., Vol. 31, No.1, January, 2017 


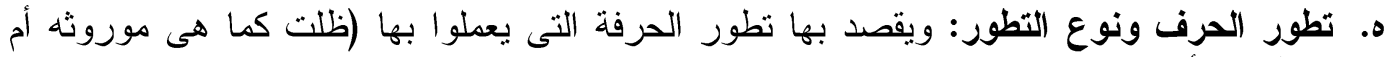

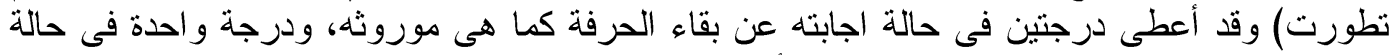

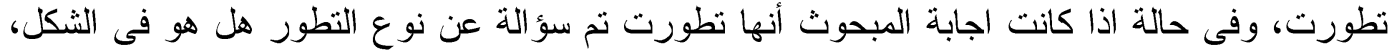

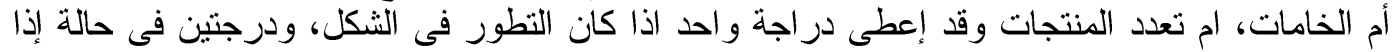

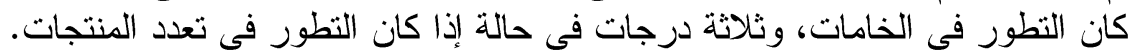

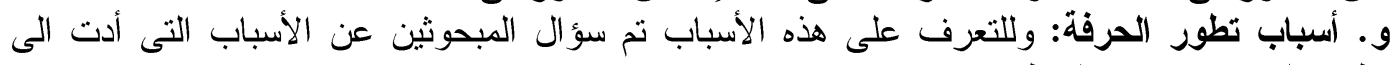

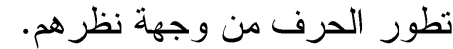
r. المشكلات التى تواجة أصحاب الحرف البيئية الريفية وتحد من إنتشارها: وللتعرف على هذه

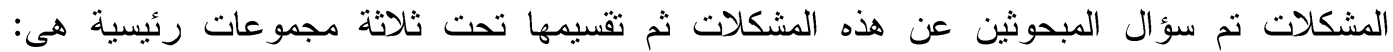

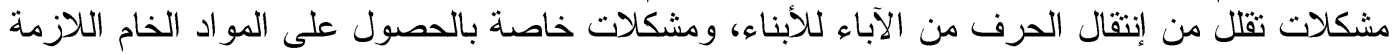

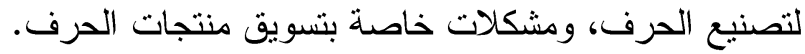

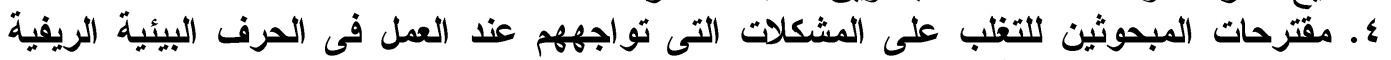

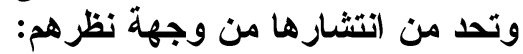
وقد تم التعرف على هذه المقترحات بسؤال المبحوثين عن مقترحاتهم للتغلب على المشكلات الى ن. اجهُمف التف على الاور الأى يمكن أن يساهم بة الإرشاد الزراعى فى مجال تنمية وتطوير الحرف البيئية الريفية:

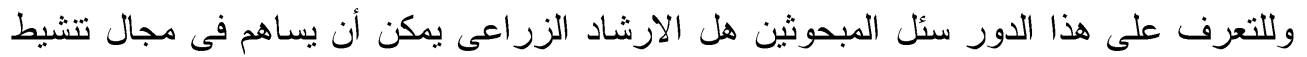

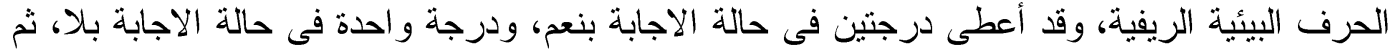

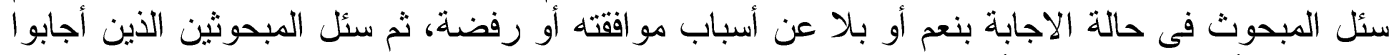

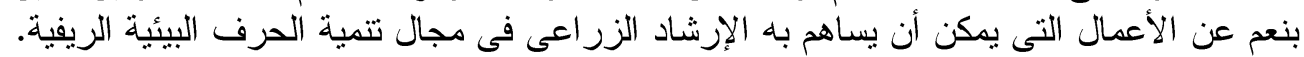

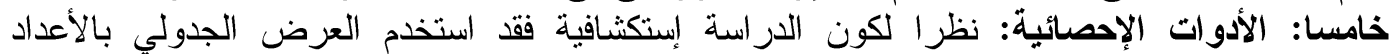
و النسب المئوية لعرض البيانات، وقد تم التعبير عن الإستجابات بطريقة وصفية بإستخدام التكرارات و النسب المئوية.

سادساً: وصف خصائص المبحوثين

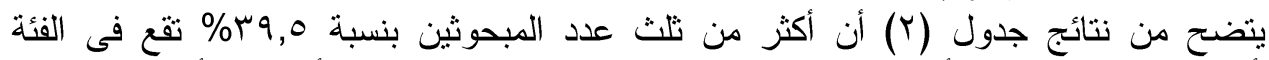

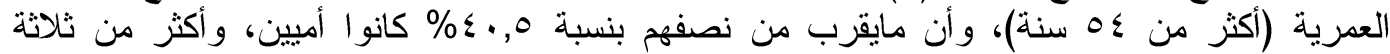

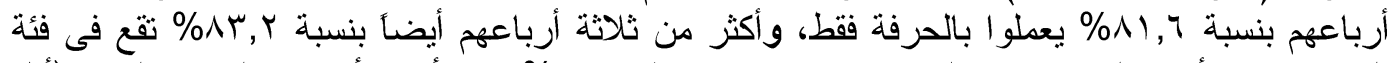

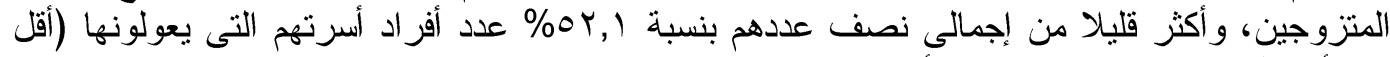

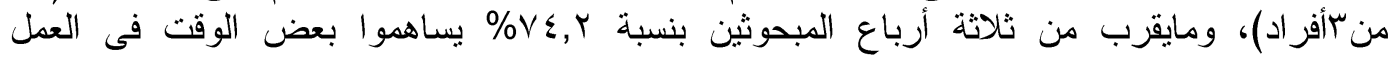

تشير النتائج السابقة إلى حدوث عزوف في الفئة العمرية المتوسطة والصغيرة السن عن العمل

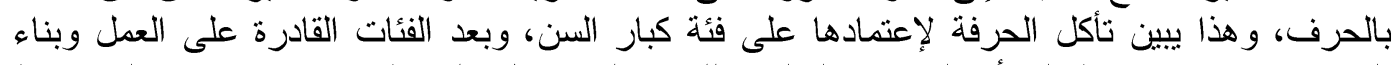

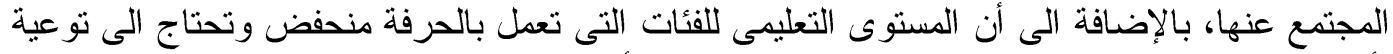

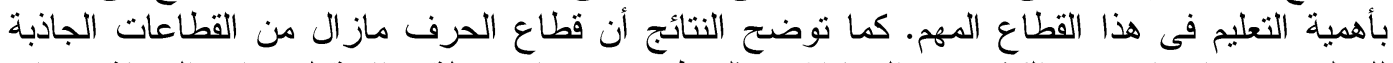

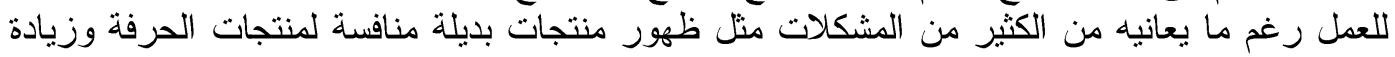

Fayoum J. Agric. Res. \& Dev., Vol. 31, No.1, January, 2017 
1.

أسعار مستلزمات الإنتاج، وأن المجتمعات الحرفية ماز الت تحتفظ بعادات وتقاليد القرى وتزويج الأبناء فى سن مبكر وهذا يدل على أنه ماز ال يوجد إستقرار لدى الأشخاص فيى القرى الريفية. وأن الغالبية

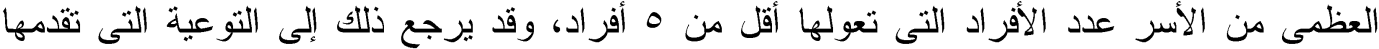

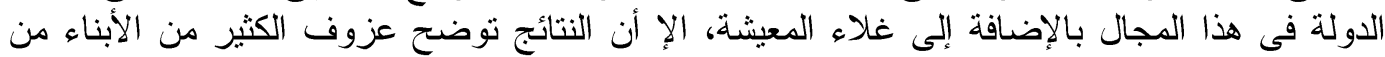

العمل بالحرفة وقد يرجع ذلك إلى الجهد الذى يبذل فيها مقابل الدخل المتدنى منها. جدول(Y): توزيع المبحوثين وفقا لخصائصهم الشخصية المدروسية

\begin{tabular}{|c|c|c|c|}
\hline \multicolumn{2}{|r|}{ الاجمالى } & \multirow[t]{2}{*}{ الفئات } & \multirow[t]{2}{*}{ الخصائص الشخصية } \\
\hline$\%$ & عدد ن =. 19 & & \\
\hline$r V, q$ & or & أقل من ^r سنة & \multirow[t]{3}{*}{ السن } \\
\hline Tr,Y & $9 r$ & من ری - ـ0 سنــة & \\
\hline$r q, 0$ & Vo & أكثر من ؟0 سنة & \\
\hline$\varepsilon \cdot, 0$ & VV & أمي & \multirow[t]{6}{*}{ الحالة التعليمبة } \\
\hline 19,0 & $\mu v$ & يقر أ ويكتب & \\
\hline $1 \cdot, 1$ & 19 & حاصل على اعدادية & \\
\hline$r \cdot, 0$ & rq & حاصل على مؤهل متوسط & \\
\hline$\wedge, q$ & iv & حاصل على مؤ هل جامعى & \\
\hline$\cdot, 0$ & 1 & حاصل على در اسات عليا & \\
\hline$\wedge 1,7$ & 100 & الحرفة فقط & \multirow[t]{2}{*}{ المهنة } \\
\hline $1 \wedge, \xi$ & ro & الحرفة ومهنة أخرى & \\
\hline$\Delta r, Y$ & 101 & مثزوج & \multirow[t]{4}{*}{ الحالة الزواجية } \\
\hline $1 \leqslant, V$ & $r \wedge$ & أعزب & \\
\hline 1,7 & $r$ & مطلق & \\
\hline$\cdot, 0$ & 1 & 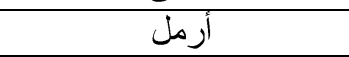 & \\
\hline or, 1 & 99 & أقل من ب أفرد & \multirow[t]{3}{*}{ عدد أفزاد الأسرة التى يعولها المبحوث } \\
\hline$r \varepsilon, V$ & 79 & من ب-ه فرد & \\
\hline$I T, Y$ & ro & أكثر من ه لأفر اد & \\
\hline $\mid Y, 1$ & $r r$ & يساهم كل الوقت & \multirow[t]{3}{*}{ مساهمة أفراد الأسرة في العمل بالحرف } \\
\hline$V \leqslant, Y$ & $1 \leqslant 1$ & يساهم بعض الوقت & \\
\hline$I T, V$ & YY & لايساهم & \\
\hline
\end{tabular}

\section{عرض التتائج ومناقشتها أولا: المعلومات الخاصة بالحرف البيئية الريفية}

يتتاول هذا الجزء من البحث عرضا لما تم التوصل إلية من معلومات عن الحرف البيئية الريفية بقرى البحث من حيث الحرف البيئة المنتشرة بالقرية، وأنواع الحرف و أكثر الأشخاص التى منى تعمل بها، وطريقة إنتقال الحرفة للأبناء، وكيفية تعلمها، وتطور الحرف ونوع التطور ، و أسبابه. أ. الحرف البيئة المنتشرة بالقرية

بينت النتائج الواردة بالجدول (r) أن أشغال الجريد كانت أكثر الحرف الموجودة بالقرية حيث إحتلت المرثبة الأولى بنسبة بلغت ، س\%، بينما إحتلت المرتبة الثانية حرفة السجاد اليدوى بنسبة بلغت

Fayoum J. Agric. Res. \& Dev., Vol. 31, No.1, January, 2017 
11

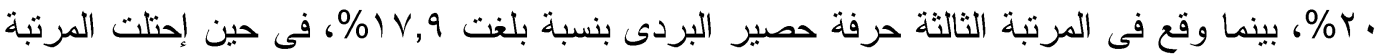

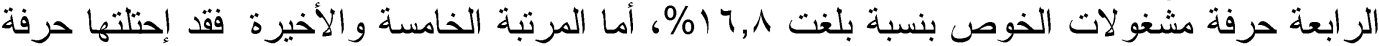

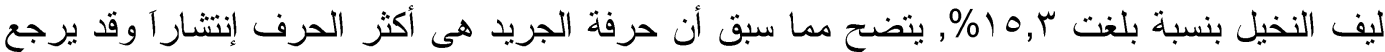

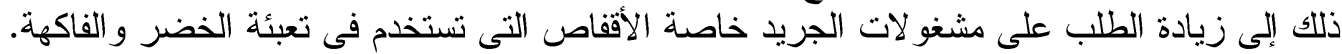

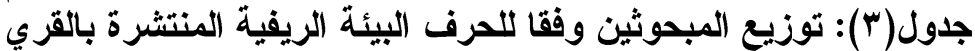

\begin{tabular}{|c|c|c|c|}
\hline$\%$ & عدد & الحرف المنتشرة بالقري & م \\
\hline$\mu \cdot, \cdot$ & OV & أشنغال الجريد & 1 \\
\hline$r \cdot, \cdot$ & $\mu \wedge$ & السجاد اليدوى & $r$ \\
\hline $1 V, 9$ & r & حصير البردى & $r$ \\
\hline 17,1 & r & مشغو لات الخوص & $\varepsilon$ \\
\hline $10, r$ & rq & ليف النخيل & 0 \\
\hline $1 \ldots$ & 19. & الحملة & \\
\hline
\end{tabular}

ب. أنواع الحرف وأكثر الأشخاص الأين يعملون بها

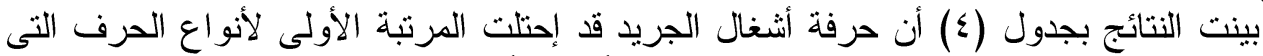
يعمل فيها المبحوثين حيث بلغت نسبنتهم

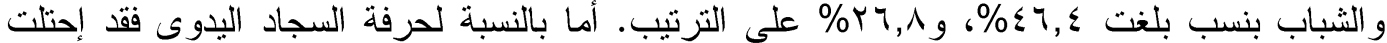

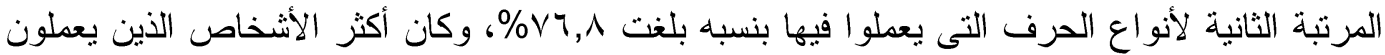

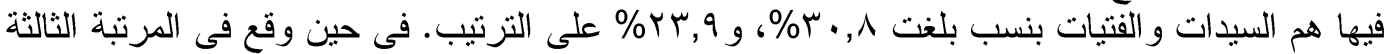

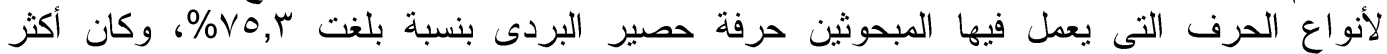

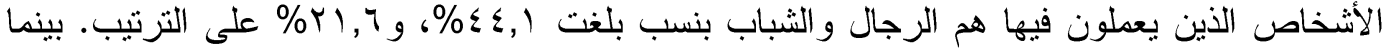

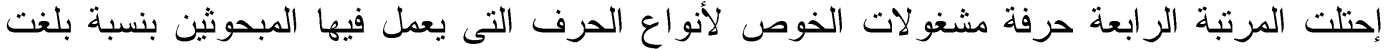

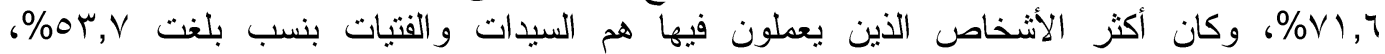

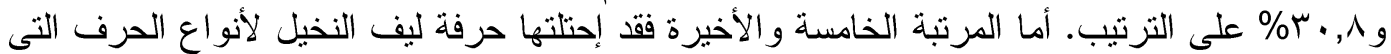

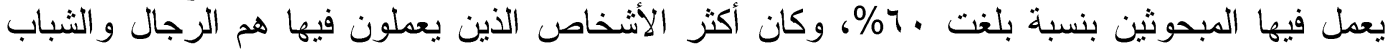

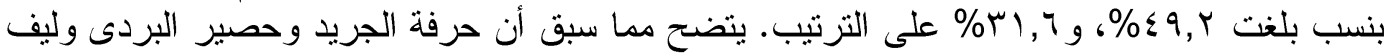

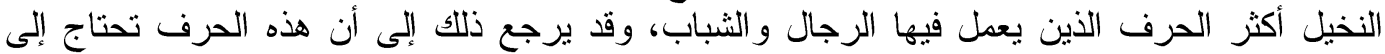

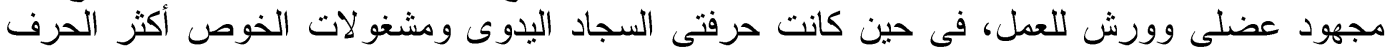

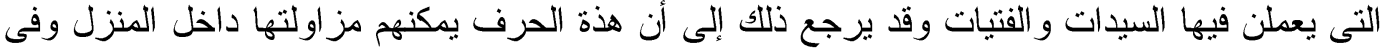

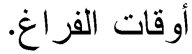

Fayoum J. Agric. Res. \& Dev., Vol. 31, No.1, January, 2017 
جدول(ع): توزيع المبحوثين المبحوثين وفقا لأنواع الحرف و أكثر الأثخاص الأين يعملون بها

\begin{tabular}{|c|c|c|c|c|c|c|c|c|c|c|c|c|}
\hline \multicolumn{10}{|c|}{ توزيع المبحوثين وفقا لأكثر الاشخاص التى تعمل بالحرفة } & \multicolumn{2}{|c|}{ المعلون بالحرفن الأين } & \multirow[t]{3}{*}{ نوع الحرف التى يعمل به القرية } \\
\hline \multicolumn{2}{|c|}{ الأطفال } & \multicolumn{2}{|c|}{ الفتيات } & \multicolumn{2}{|c|}{ الشباب } & \multicolumn{2}{|c|}{ السيدات } & \multicolumn{2}{|c|}{ الرجال } & \multirow[t]{2}{*}{$\%$} & \multirow[t]{2}{*}{ تكر ار } & \\
\hline$* \%$ & تكر ار & $* \%$ & تكر ار & $\% \%$ & تكر ار & $\% \%$ & تكرار & $* \%$ & تكر ار & & & \\
\hline$\wedge, 9$ & 10 & $1 \cdot, \mathrm{V}$ & 11 & $r Y, \wedge$ & $\leqslant 0$ & $V, r$ & Ir & $\leqslant\rceil, \xi$ & VA & $\wedge \wedge, 0$ & 171 & أشغال الجريد \\
\hline $1 \leqslant, \varepsilon$ & YI & $r r, q$ & ro & 10,1 & Yr & $\Gamma \cdot, \wedge$ & $\leqslant 0$ & 10,1 & Tr & $\vee \curlyvee, \wedge$ & $1 \leq 7$ & السجاد اليدوى \\
\hline $7, r$ & 9 & $1 Y, 7$ & 11 & Y), & M & $10, \varepsilon$ & TY & $\varepsilon \varepsilon, 1$ & $4 \pi$ & $V 0, r$ & $1 \leq \pi$ & حصير البردى \\
\hline- & - & $\Gamma \cdot$, & $\sum Y$ & $\Lambda, 1$ & 1. & or, & $V \mu$ & $V, \Sigma$ & 1. & 91,7 & 4ו & مشغولات الخوص \\
\hline- & - & 9,7 & 11 & T, T & צוץ & 9,7 & 11 & $\varepsilon 9, Y$ & 07 & 7. & $11 \varepsilon$ & ليف النخيل \\
\hline
\end{tabular}

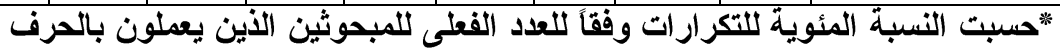

ج. طريقة إنتقال الحرف للأبباء

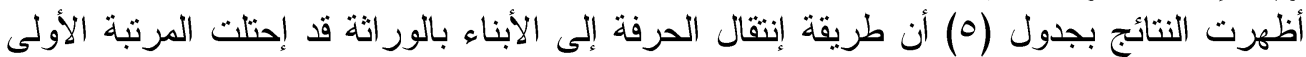

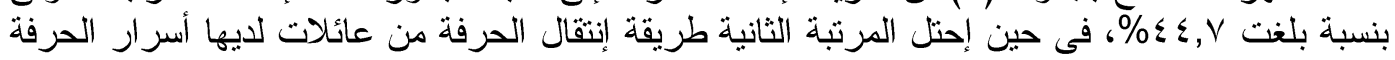

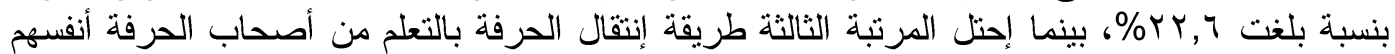

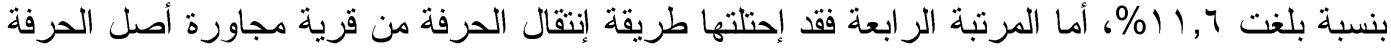

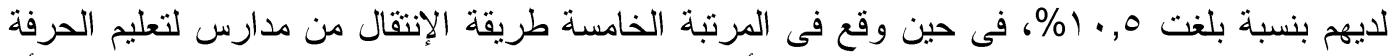

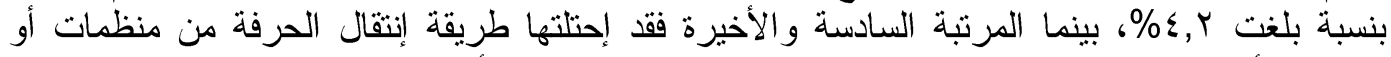

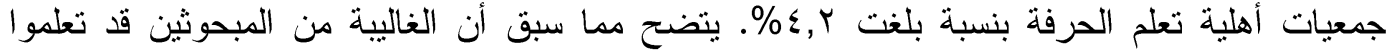

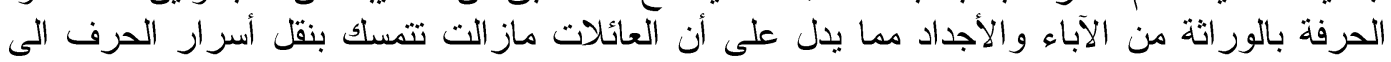
أبنائها من الأجيال الجديدة. جدول(0): توزيع المبحوثين وفقا لطريقة إنتقال الحرف البيئية الريفية الإلى الأبناء

\begin{tabular}{|c|c|c|c|}
\hline$\%$ & عدد & طريقة الإتقال & 5 \\
\hline$\varepsilon \varepsilon, V$ & 10 & بالور اثة & i \\
\hline YY,T & $\varepsilon r$ & من عائلات لديها اسر ار الحرفة & r \\
\hline 11,7 & rr & التعلم من اصحاب الحرفة انفسهر & $r$ \\
\hline $1 \cdot, 0$ & $r \cdot$ & من قرية مجاورة اصل الحرفة لديهم & $\varepsilon$ \\
\hline $7, r$ & Ir & مدارس لتعليم الحرفة & 0 \\
\hline$\varepsilon, Y$ & $\wedge$ & منظمات او جمعيات أهلية تعلم الحرفة & 7 \\
\hline $1 \cdots, \cdot$ & 19. & جملة & \\
\hline
\end{tabular}

د. كيفية تعلم الأشخاص الحرف

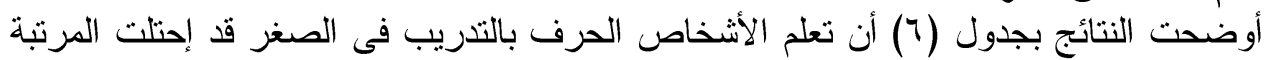

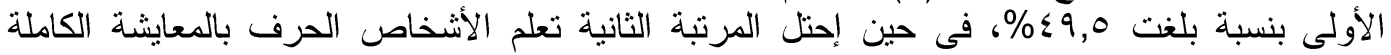

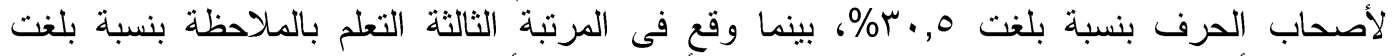

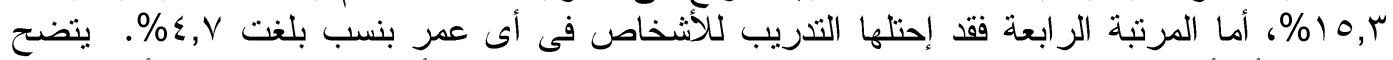

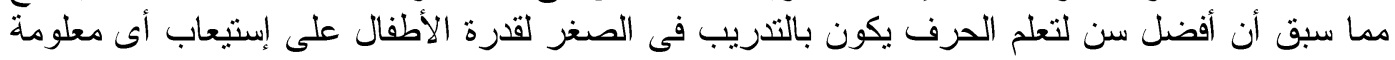
بسهولة.

Fayoum J. Agric. Res. \& Dev., Vol. 31, No.1, January, 2017 
جدول(َ): توزيع المبحوثين وفقاً لكيفية تعلم الأثخاص الحرف البيئية الريفية

\begin{tabular}{|c|c|c|}
\hline$\%$ & عدد & تعلم الحرف \\
\hline$\leqslant 9,0$ & $9 \leq$ & بالتدريب من الصغر \\
\hline$r \cdot, 0$ & 01 & بالمعايشة الكاملة لأصحاب الحرفة \\
\hline $10, \Gamma$ & rq & بالملاحظة \\
\hline$\varepsilon, V$ & 9 & بالتدريب للأشخاص فى أى عمر \\
\hline$\ldots$ & 19. & جملة \\
\hline
\end{tabular}

ه. تطور الحرف ونوع التطور

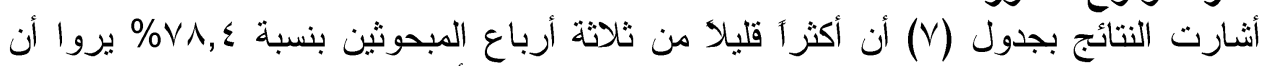

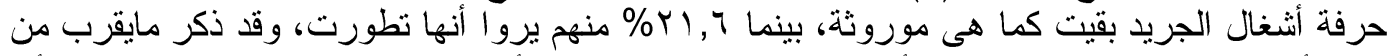

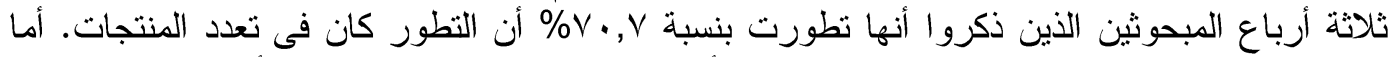

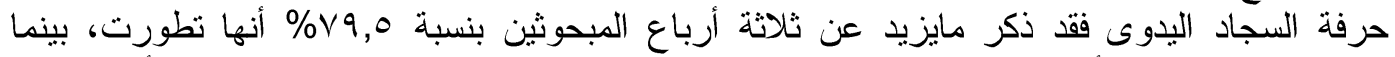

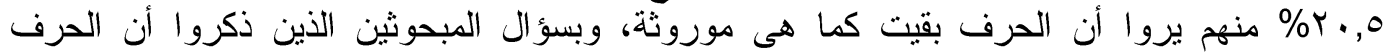

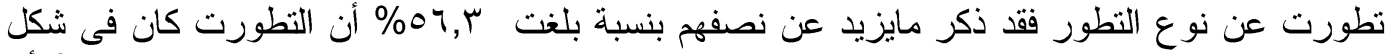

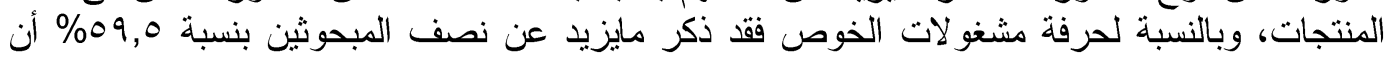

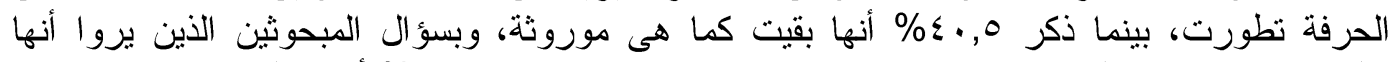

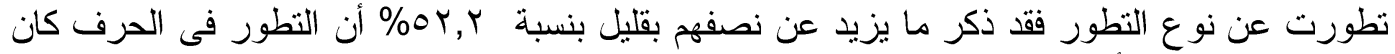

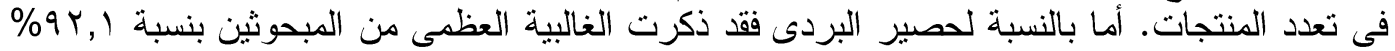

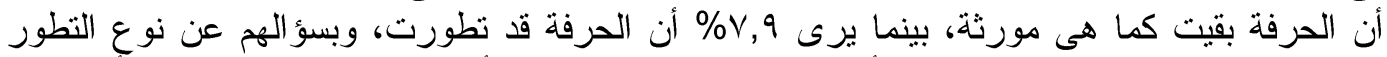

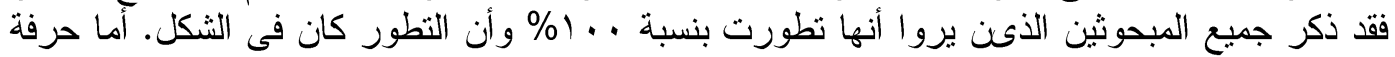

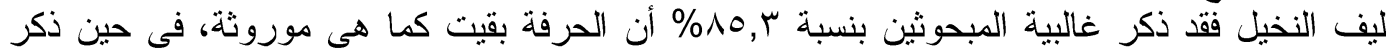

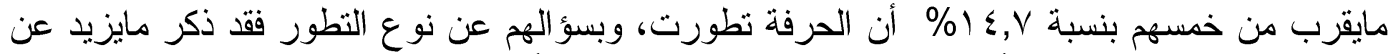

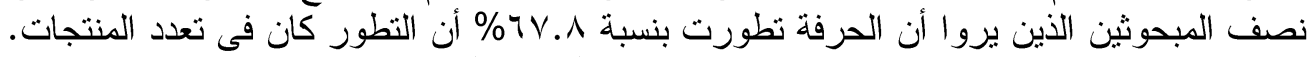

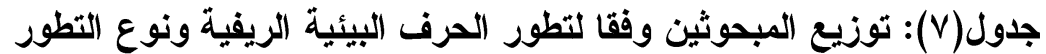

\begin{tabular}{|c|c|c|c|c|c|c|c|c|c|c|}
\hline \multicolumn{6}{|c|}{ نوع التطور } & \multicolumn{4}{|c|}{ نطور الحرف ن=، 19 } & \multirow[t]{3}{*}{ البيان } \\
\hline \multicolumn{2}{|c|}{ تعدد المنتجات } & \multicolumn{2}{|c|}{ الخامات } & \multicolumn{2}{|c|}{ الثكل - الثل } & \multicolumn{2}{|c|}{ تطورت } & \multicolumn{2}{|c|}{ كماهى موروثثة } & \\
\hline$\%$ & عدد & $\%$ & 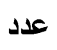 & $\%$ & عدد & $\%$ & 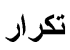 & $\%$ & 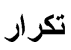 & \\
\hline$V \cdot, v$ & $r q$ & - & - & $r q, r$ & 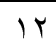 & $r), 7$ & §1 & $\vee \wedge, \varepsilon$ & $1 \leqslant 9$ & أنتخغال الجريد \\
\hline $10, Y$ & $r \mu$ & $r \wedge, 0$ & $\varepsilon r$ & $07, r$ & 10 & $V 9,0$ & 101 & $r \cdot, 0$ & $r q$ & السجاد البدوى \\
\hline$O Y, Y$ & 09 & $1 \cdot, 7$ & Ir & $r V, r$ & $\xi Y$ & 09,0 & $\pi \Gamma$ & $\xi \cdot, 0$ & $V V$ & مشغو لات الخوص \\
\hline- & - & - & - & $1 \ldots$ & 10 & $v, q$ & 10 & $9 Y, 1$ & ivo & حصير البردى \\
\hline$T V, \Lambda$ & 19 & $1 \varepsilon, r$ & $\varepsilon$ & 18,9 & 0 & $1 \leqslant, V$ & $r \wedge$ & $\wedge 0, r$ & $17 Y$ & ليف النخيل \\
\hline
\end{tabular}

Fayoum J. Agric. Res. \& Dev., Vol. 31, No.1, January, 2017 


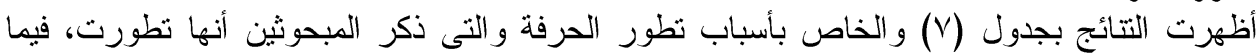

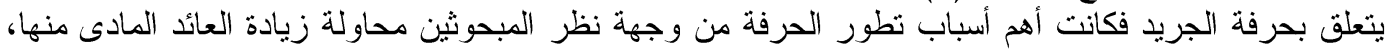

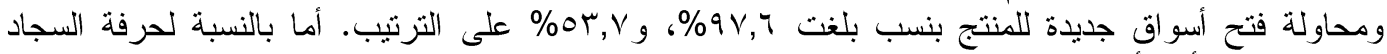

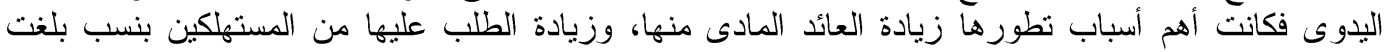

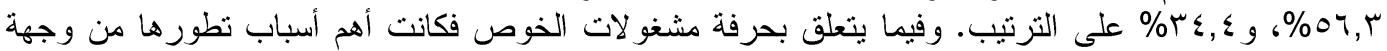

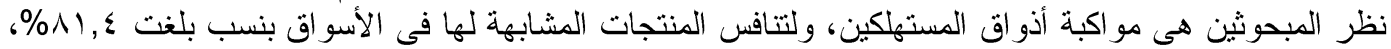

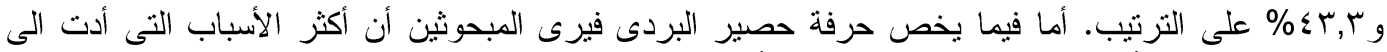

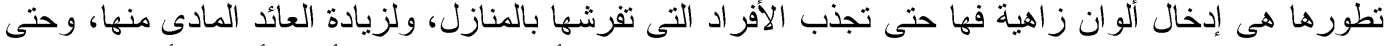

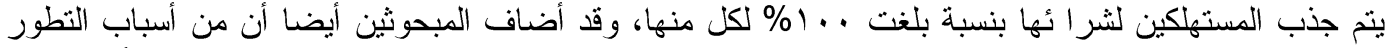

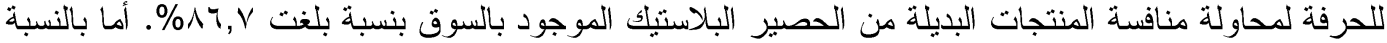

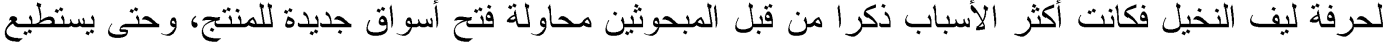

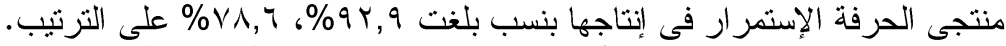
(V) توزيع المبحوثين وفقا لأسباب تطور الحرف البيئية الريفية

\begin{tabular}{|c|c|c|c|}
\hline$\%$ & التكرارت & اسباب تظور الحرف & s \\
\hline \multicolumn{4}{|c|}{ الجريلن=إ؛ } \\
\hline $9 Y, 7$ & $\varepsilon$. & محاولة زيادة العائد المادى منها & 1 \\
\hline $0 \mathrm{OT,V}$ & Tr & محاولة فتح اسو اق جديدة للمنتج & $r$ \\
\hline$r \varepsilon, 1$ & $1 \varepsilon$ & زيادة الطلب على الحرفة & $\Gamma$ \\
\hline$r 4, \Lambda$ & 11 & مو اكبة أذواق المستهكين و إحتياجاتهم & $\underline{\varepsilon}$ \\
\hline \multicolumn{4}{|c|}{ السجاد اليلاوى ن= 101} \\
\hline $07, \Gamma$ & 1. & زيادة العائد المادى منها & 1 \\
\hline$r \varepsilon, \varepsilon$ & Or & زيادة الطلب عليها من المستهلكين & $r$ \\
\hline$T Y, \Lambda$ & $\varepsilon r$ & محاولة فتح أسو اق جديدة & $r$ \\
\hline$r \mu, \Lambda$ & $r 9$ & تو اكب أذو اق المستهلكين & $\varepsilon$ \\
\hline \multicolumn{4}{|c|}{ 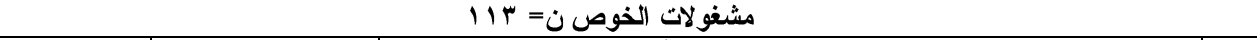 } \\
\hline$\Lambda, \varepsilon$ & Qr & مو اكبة أذوق المستهلكين من الأجانب & 1 \\
\hline$\varepsilon r, \Gamma$ & «9 & نتافس المنتجات المشابهة لها في الأسو اق & $r$ \\
\hline$r r, 1$ & ro & تمشيا مع طلبات اصحاب القرى السياحية & $r$ \\
\hline$r, r$ & $r \varepsilon$ & زيادة العائد المادى منها & $\varepsilon$ \\
\hline \multicolumn{4}{|c|}{ حصير البردى ن = 10} \\
\hline $1 \ldots$ & 10 & إدخال ألو ان زاهية فيها حتى تجذب الأفر ادالتي تفرشها بالمنازل & 1 \\
\hline $1 \cdots$ & 10 & زيادة العائد المادى منها & $r$ \\
\hline $1 \ldots$ & 10 & حتى يتم جذب المستهلكين لثر ائها & $r$ \\
\hline 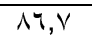 & $1 \%$ & محاولة منافسة المنتجات البديلة من الحصير البلاستيك الموجود بالسوق & $\varepsilon$ \\
\hline$V \mu, r$ & 11 & زيادة الطلب عليها من منتجى البلح بفرش البلح عليها & - \\
\hline 14,14 & r & زيادة الطلب عليها من أصحاب القرى السياحية & 7 \\
\hline \multicolumn{4}{|c|}{ ليف النخيل ن= YA } \\
\hline 94,9 & rT & محاولة فتح أسو اق جديدة للمنتج & 1 \\
\hline$V \wedge, 7$ & ru & حتى يستطيع منتجى الحرفة الاستمر ار في إنتاجها & $r$ \\
\hline$\varepsilon \Gamma, \Gamma \wedge$ & Ir & محاولة زيادة العائد المادى منها & $r$ \\
\hline
\end{tabular}

Fayoum J. Agric. Res. \& Dev., Vol. 31, No.1, January, 2017 
ثانيا: المشكلات التى تواجة أصحاب الحرف البيئية الريفية وتحد من انتشارها

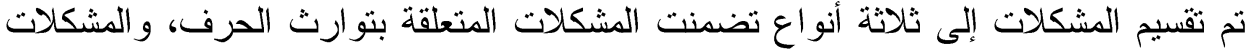

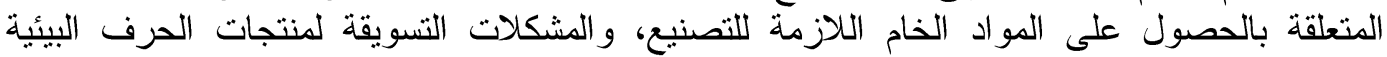
الريفية وسوف يتم توضيح كل مشكلة على على حدة. أ. المشكلات المتعلقة بتوارث الحرف

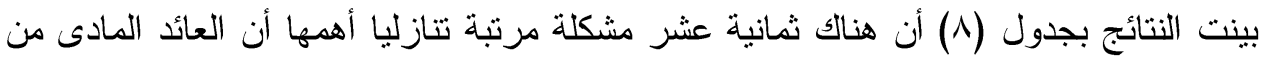

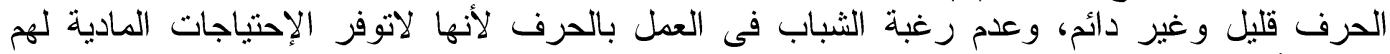

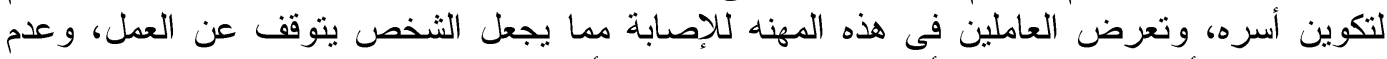

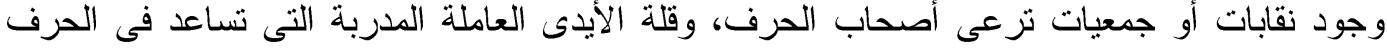

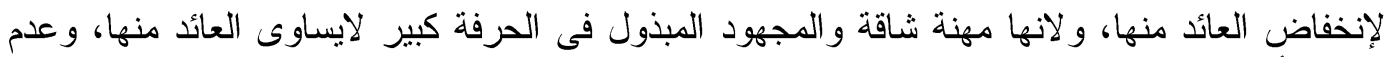

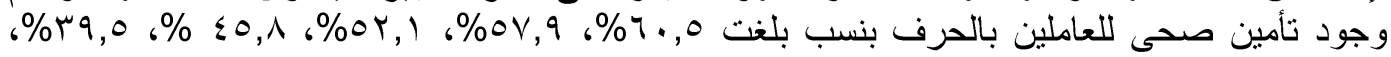

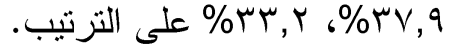
جذول ( 1 ): توزيع المبحوثين وفقاً للمشكلات المتعلقة بتوارث الحرف البيئية الريفية مرتبة تنازليا

\begin{tabular}{|c|c|c|c|}
\hline$\%$ & 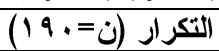 & المشكلات & r \\
\hline 7.0 & 110 & العائد المادى من الحرفة قليل و غير دائم & 1 \\
\hline $0 \vee .9$ & 11. & عدم رغبة الثباب فى العمل بالحرفة لأنها لاتوفر الإحتياجات المادية لهم لتكوين أسره & r \\
\hline OY.1 & 99 & تعرض العاملين في هذه المهنه للإصابة مما يجعل الثخص يتوقف عن العمل & $\mu$ \\
\hline$\varepsilon 0 . \wedge$ & $\wedge \vee$ & عدم وجود نقابات أو جمعيات ثرعى أصحاب الحرفة & $\xi$ \\
\hline$r 9.0$ & Vo & قلة الأيدى العاملة المدربة التى تساعد في الحرفة لانخفاض العائد منها & 0 \\
\hline$r V, q$ & VY & لانها مهنة شاقة و المجهود المبذول فى الحرفة كبير لايساوى العائد منها & 7 \\
\hline$M T, Y$ & $4 \pi$ & عدم وجود تأمين صحى للعاملين بالحرفة & $\mathrm{V}$ \\
\hline$r 9,0$ & 07 & عدم توفير الدولة معارض لعرض ماينتج من الحرف فيها & $\wedge$ \\
\hline$r 9,0$ & 07 & لأن الحرفة ليس لها ضمان صحى أو مادى أو معاش & 9 \\
\hline$r \wedge, q$ & 00 & الحرفة عائدها قليل ويومى & 1. \\
\hline$r V, \xi$ & or & عدم رغبة الأهل في تعلم أو لادهم الحرفة لضعف العائد منها & 11 \\
\hline Yr, & $\varepsilon r$ & قلة الطلب على منتجات الحرفة & IY \\
\hline Yr,T & $\leqslant \mu$ & عدم تقديم أى رعاية لأصحاب الحرف من جهة الدولة & 14 \\
\hline$r \cdot, \cdot$ & $r \Lambda$ & ليس لها عائد مادى مجزى مقارنة بأسعار الخامات & $1 \varepsilon$ \\
\hline 9,0 & 11 & عدم وجود جمعية أو نقابة تدافع حقوق أصحاب الحرف & 10 \\
\hline $7, r$ & IT & فى حالة الإصابة أو المرض لايكون هناك دخل & 17 \\
\hline$\varepsilon, V$ & 9 & أن الحرفى ممكن أن يعمل فترة ويوقف العمل مدة & 18 \\
\hline$\cdot, 0$ & 1 & عدم دعم الدولة للصناعات الحرفية من خلال تأمنيات أو معاشات شاملة & 11 \\
\hline
\end{tabular}

Fayoum J. Agric. Res. \& Dev., Vol. 31, No.1, January, 2017 
ب. المشكلات المتعلقة بالحصول على المواد الخام اللازمة لتصنيع الحرفة

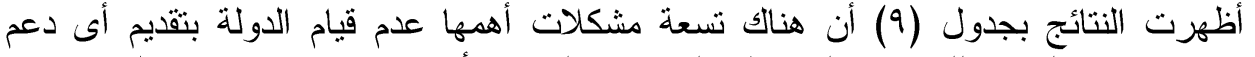

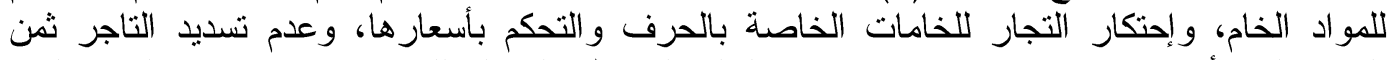

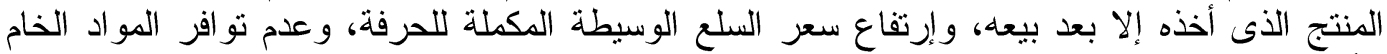

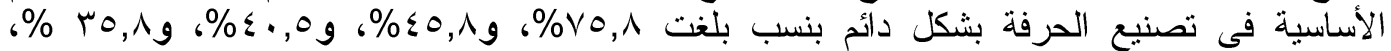

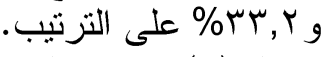
جدول (9): توزيع المبحوثين وفقاً للمشكلات المتعلقة بالحصول على المواد الخام اللازمة لتصنيع الحرف البيئية الريفية مرتبة وفئة تنازليا

\begin{tabular}{|c|c|c|c|}
\hline$\%$ & ن= التكرار 9 & مشكلات الحصول على المواد الخام & b \\
\hline $\mathrm{V} 0, \Lambda$ & $1 \leqslant \varepsilon$ & عدم قيام الدولة بتقديم أى دعم للمو اد الخام & 1 \\
\hline$\S 0, \wedge$ & AV & إحتكار التجار للخامات الخاصة بالحرف و التحكم بأسعار ها & r \\
\hline$\xi \cdot, 0$ & VV & عدم تسديد التاجر ثمن المنتج الذي اخذه إلا بعد بيعه & $r$ \\
\hline$r 0, \Lambda$ & 71 & إرتفاع سعر السلع الوسيطة المكملة للحرفة & $\varepsilon$ \\
\hline$T r, r$ & Tז & عدم تو افر المو اد الخام الأساسية في تصنيع الحرفة بشكل دائح & 0 \\
\hline$r \wedge, \varepsilon$ & ه & إرتفاع أسعار المو اد الخام لقلة المعروض منها & 9 \\
\hline$r \cdot, 0$ & rq & تسويق المنتج ضعيف لأنه يتم تسويقة بشكل موسمي & $\mathrm{V}$ \\
\hline 19,0 & rV & وجود منتجات بديلة أرخص و أسهل فى الإستعمال ويعيش مدة أطول & $\wedge$ \\
\hline 11,9 & די & عدم وجود أسو اق خاصة لبيع المنتج & 9 \\
\hline
\end{tabular}

ج. المشكلات التسويقية لمنتجات الحرف البيئية الريفية

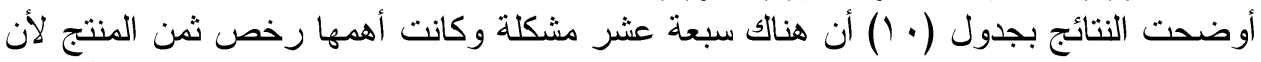

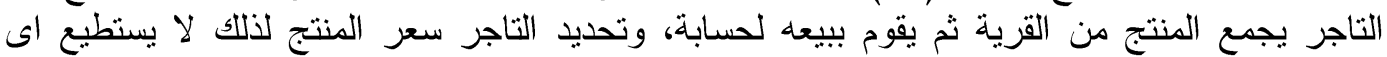

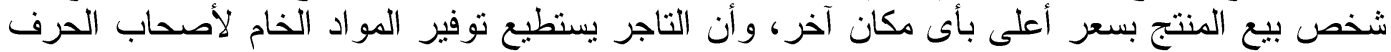

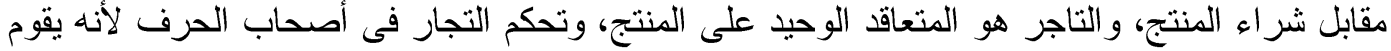

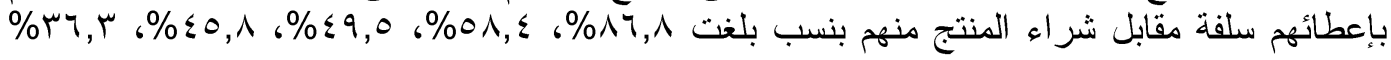
على الترتيب.

Fayoum J. Agric. Res. \& Dev., Vol. 31, No.1, January, 2017 
IV

جدول ( • (): توزيع المبحوثين وفقاً للمشكلات الخاصة بتسويق منتجات الحرف البيئية الريفية مرتبة تنازليا

\begin{tabular}{|c|c|c|c|}
\hline$\%$ & ن & مشكلات التسويق & ? \\
\hline$\wedge \uparrow, \wedge$ & 170 & رخص ثمن المنتج لأن التاجر يجمع المنتج من القرية ثم يقوم بييعه لحسابة & 1 \\
\hline $0 \wedge, \xi$ & 111 & تحديد التاجر سعر المنتج لذلك لا يستطيع أى شخص بيع المنتج بسعر أعلى بأى مكان آخر & r \\
\hline$\{9,0$ & $9 \varepsilon$ & أن التاجر يستطيع توفير المو اد الخام لأصحاب الحرف مقابل شر اء المنتج & $r$ \\
\hline$£ 0,1$ & $\Lambda V$ & التاجر هو المتعاقد الوحيد على المنتج & $\varepsilon$ \\
\hline$r \bar{r}$ & 79 & تحكم التجار فى أصحاب الحرف لأنه يقوم بإعطائهم سلفة مقابل شر اء المنتج منهم & 0 \\
\hline$r \varepsilon, V$ & 77 & التاجر هو صاحب رأس المال لذلك هو الذى يحدد سعر الثر اءوسعر البيع & 7 \\
\hline ru, & 74 & يتحكم التاجر في سعر الييع و الثر اء لانه هو الذى يعرض المنتج فى السوق & $\begin{array}{l} \\
\end{array}$ \\
\hline$r \wedge, \xi$ & $0 \leqslant$ & لأن التاجر يكون على معرفة جيدة بالأسو اق الخارجية & $\Lambda$ \\
\hline TV, & or & عدم حماية المنتج من قبل الدول و استير اد بدائل له بأسعار رخيصة & 9 \\
\hline ro,r & $\leqslant 1$ & قلة إقبال المستهلكين على شر اء المنتج لوجود بدائل مصنعة من البلاستيك أقل فى السعر & 1. \\
\hline YY,Y & $\varepsilon r$ & رخص ثمن المنتج لبيعة فى سوق القرية & 11 \\
\hline IV, 9 & T乏 & يشترى التاجر المنتج بسعر رخيص جدا لانه ياخذه جملة & IY \\
\hline $1 \wedge, 9$ & rT & عدم وجود ر ابطة أو نقابة تحمى اصحاب الحرف من جشع التجار & ir \\
\hline$i V, \varepsilon$ & r & عدم معرفة كثير من اصحاب الحرف الوصول لأسو اق العاصمة & $1 \varepsilon$ \\
\hline 11,7 & YY & عدم وجود أسو اق دائمة لبيع المنتج & 10 \\
\hline $\mathrm{V}, \mathrm{q}$ & 10 & عدم وجود معارض دائمة للمنتجات داخل المحافظة أو خارجها لعرض المنتج بها & 17 \\
\hline$\wedge, 9$ & IV & عدم وجود بعض الهيئات و الجمعيات نتبنى عملية التسويق للتخلص من الوسطاء & IV \\
\hline
\end{tabular}

ثالثاً: مقترحات المبحوثين للتظلب على المشكلات التى تواجههم عند العمل فى الحرف البيئية الريفية وتحد من إنتشار هات المبان

بينت النتائج بجدول (11) أن هنار هاك ثمانية مقترحات ذكرها المبحوثين كانت أهمها عمل تأمين

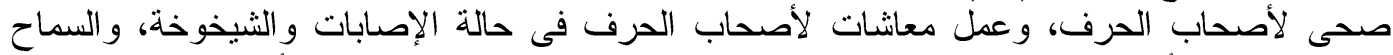

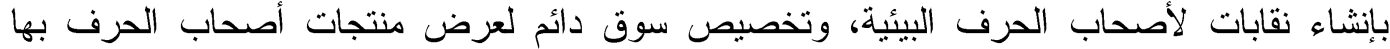

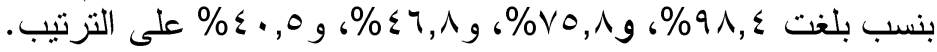

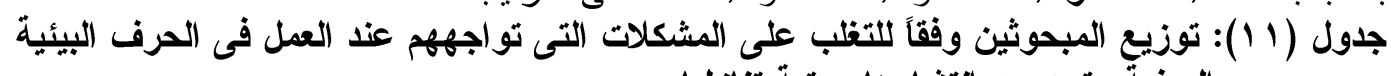

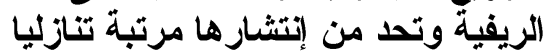

\begin{tabular}{|c|c|c|c|}
\hline$\%$ & أتكر ارات 19 & المقترحات & $p$ \\
\hline $9 \wedge, \xi$ & $1 \wedge V$ & عمل تأمين صحى لأصحاب الحرف & 1 \\
\hline$\vee \vee, \Lambda$ & $1 \leq \varepsilon$ & عمل معاشات لأصحاب هذه الحرف في حالة الإصابات و الثنيخوخة & r \\
\hline$\leqslant\rceil, \wedge$ & 19 & السماح بإنشاء نقابات لأصحاب الحرف البيئية & $r$ \\
\hline$\varepsilon \cdot, 0$ & VV & تخصيص سوق دائم لعرض منتجات أصحاب الحرف بها & $\varepsilon$ \\
\hline $1 \%, r$ & ro & توفير الدعم المادى من الحكومة لأصحاب الحرفة & 0 \\
\hline $1 \wedge, 9$ & r & عقد دورات تدرييية لنشجيع الثباب على تعلم الحرفة & 7 \\
\hline $1 \cdot, \cdot$ & 19 & تشجيع المستهلكين على العودة لثر اء المنتجات البيئية & $\mathrm{V}$ \\
\hline $7, \wedge$ & 14 & إنثاء جمعيات لحماية أصحاب الحرف & $\wedge$ \\
\hline
\end{tabular}

Fayoum J. Agric. Res. \& Dev., Vol. 31, No.1, January, 2017 
11

رابعاً: التعرف على الاور الأى يمكن أن يساهم بة الإرشاد الزاعى فى مجال تنمية وتطوير الحرف البيئية الريفية النعرف عابة

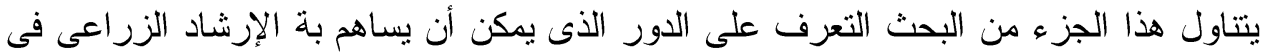

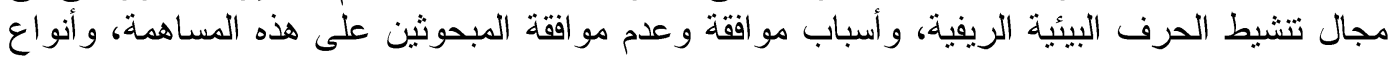

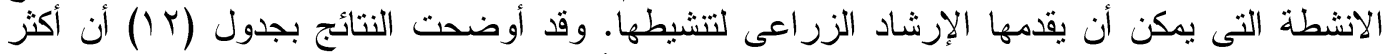

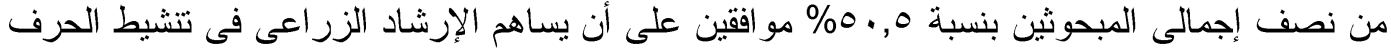

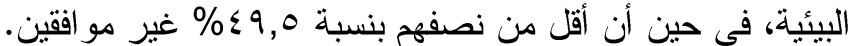

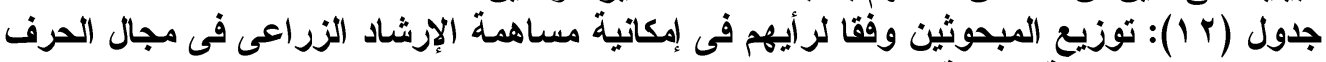
البيئية الريفية المبية

\begin{tabular}{|c|c|c|}
\hline \multicolumn{2}{|c|}{ أجمالى } & \multirow[t]{2}{*}{ مساهمة الإرشاد } \\
\hline$\%$ & عدد & \\
\hline $0 ., 0$ & 99 & نعم \\
\hline$\leqslant 9,0$ & $9 \xi$ & $\gamma$ \\
\hline $1 \ldots$ & 19. & الجملة \\
\hline
\end{tabular}

وبسؤ ال المبحوثين عن أسباب مو افقتهم و هذا ما بينته نتائج جدول (ب أ) و الذى تضمن سبعة أسباب كان

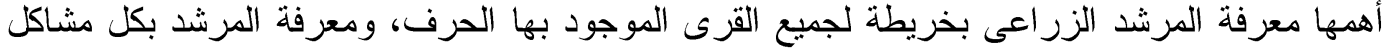

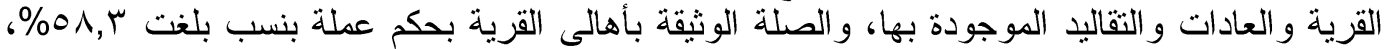

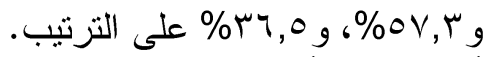

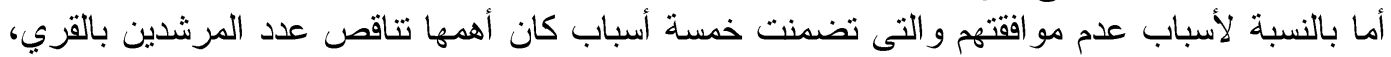
وغياب المرشد غالبية الاوقات، وعدم وجود وسيلة إنتقال سريعة تمكن المرشد من التتقل داخل القرية القرية

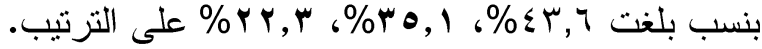

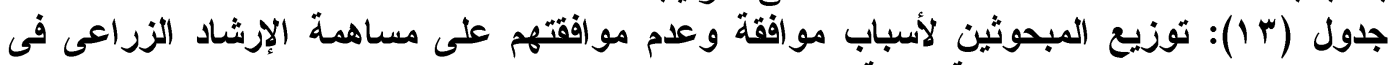
مجال الحرف البيئية مرتبة لنازياب لاسيا

\begin{tabular}{|c|c|c|c|}
\hline$\%$ & 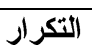 & الأسباب & م \\
\hline \multicolumn{4}{|c|}{ أولاً: أسباب الموا(فقة ن= 94} \\
\hline$\Delta \wedge, \Gamma$ & 07 & معرفة المرشد الزر اعى بخريطة لجمبع القزى الموجود بها الحرف البيئية الريفية & $T$ \\
\hline$\Delta V, r$ & 00 & معرفته بكل مشاكل القرية والعادات و التقاليد الموجودة بها & $r$ \\
\hline rq,o & ro & الصلة الوثيقة بأهالى القرية بحكم عملة & $r$ \\
\hline r & re & علاقته الطيبه بجميع أهالى القرية & $\varepsilon$ \\
\hline$r r, q$ & $r r$ & أنة يتبع جهة حكومية يمكن الرجوع الى مكانه فى أى وقت & 0 \\
\hline 10,7 & 10 & قدرته على توفير إمكانيات استخدام أسلوب الإيضاح العملى بالمشاهدة & 7 \\
\hline $1 \%, 0$ & 14 & لدية خبرة كبيرة في مجال التدريب و التعامل مع الكبار & $\mathrm{V}$ \\
\hline \multicolumn{4}{|c|}{ 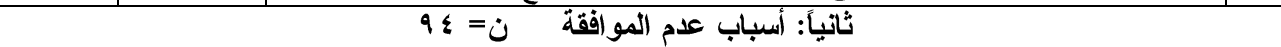 } \\
\hline$\varepsilon \Psi, \uparrow$ & \&1 & تناقص عدد المرشدين بالقري & 1 \\
\hline$r 0,1$ & r & غياب المرشد غالبية الأوقات & $r$ \\
\hline$r, r$ & Y & عدم وجود وسيلة إنتقال سريعة تمكن المرشد من التتقل داخل القرية & $\varepsilon$ \\
\hline 19,1 & 11 & كبر سن المرشُدين الموجودين بالقرى & $r$ \\
\hline IV,. & 17 & تكليف المرشد بأدوار أخرى غير عملة & 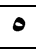 \\
\hline
\end{tabular}

Fayoum J. Agric. Res. \& Dev., Vol. 31, No.1, January, 2017 
19

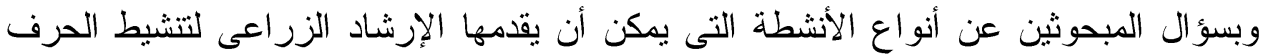

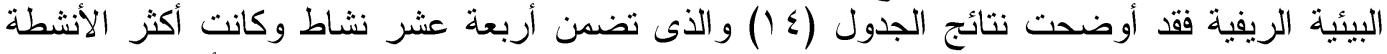

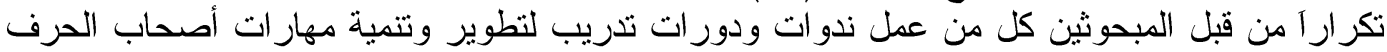

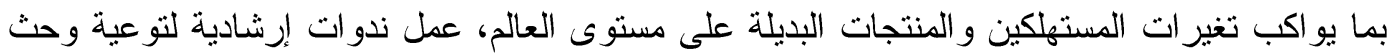

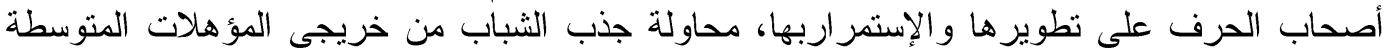

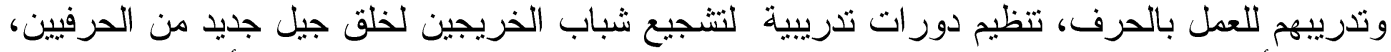

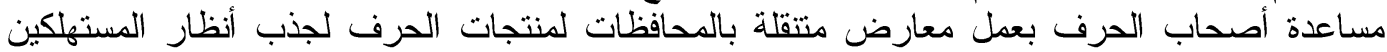

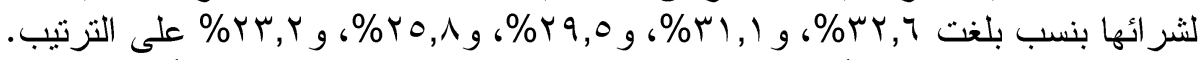

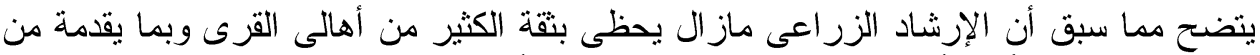

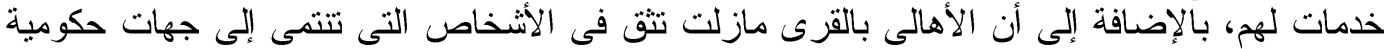

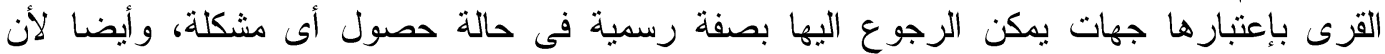

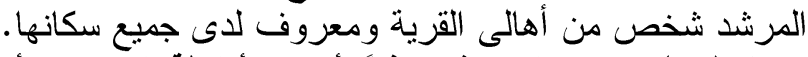
جدول (ع 1): توزيع المبحوثين وفقاً لأنواع الأثشطة التى يمكن أن يقامها الإرشاد الزراعى لتنشيط الحرف

\begin{tabular}{|c|c|c|c|}
\hline \\
\hline$\%$ & $\begin{array}{l}\text { (التكرار } \\
19 .=0\end{array}$ & الأنثطة التى يمكن أن يقدمها الإرشاد الزراعى & م \\
\hline Tr,T & TY & 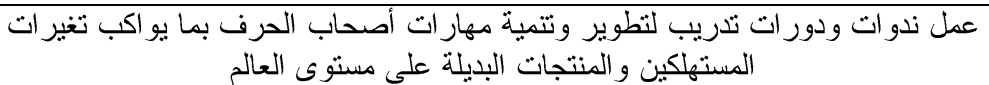 & 1 \\
\hline$r, 1$ & 09 & عمل ندوات إرشادية لتو عية وحث أصحاب الحرف على تطوير ها و الإستمر ار بها & r \\
\hline$r 9,0$ & 07 & محاولة جذب الثنباب من خريجى المؤهلات المنوسطة وتدرييهر للعمل بالحرف & 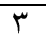 \\
\hline ro, 1 & $\leqslant 9$ & تتظيم دور ات تدرييية لتتجيع شباب الخريجين لخلق جيل جديد من الحرفيين & $\varepsilon$ \\
\hline$T r, Y$ & $\xi \varepsilon$ & مساعدة أصحاب الحرف بعمل معارض منتقلة بالمحافظات لمنتجات الحرف لجذب أنظار & 0 \\
\hline$T, T$ & \&1 & المساعدة فى توعية أصحاب الحرف بأهمية المحافظة على بقاء الحرف وتطوير ها & 9 \\
\hline r. & rᄉ & تدريب أصحاب الحرف على تطوير ها حتى تتافس عالميا وتمثل عنصر جذب للسائحين & $\mathrm{V}$ \\
\hline $1 \Lambda, \xi$ & ro & المساعدة لأصحاب الحرف فى عمل اعلانات عنها & $\Lambda$ \\
\hline 17,1 & Tr & تسهيل و إرشاد السياح لأماكن تصنيع الحرف بالقزى & 9 \\
\hline $17, \Gamma$ & T) & تدريب أصحاب الحرف على كيفية توقير مايجتاجونه من متطلبات لتصنيع الحرف & 1. \\
\hline 10,1 & $r$. & المساعدة فى عمل معارض دائمة يعرض فيها منتجات الحرف و إعتبار ها مز ار سياحى & 11 \\
\hline $1 \leqslant, Y$ & TV & مساعدة أصحاب الحرف فى معرفة المصادر التى يمكن أن تقدم لهم دعم مالى للحصول & Ir \\
\hline 11,7 & Tr & 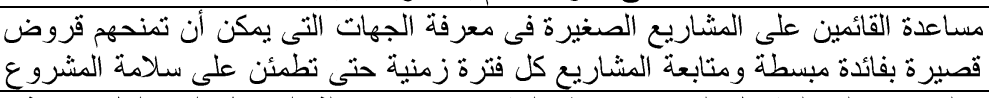 & 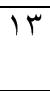 \\
\hline 9,0 & 11 & التعرف على المشاكل التى تعوق هذه المشرو عات ومحاولة التوصل إلى حلول مناسبة & $1 \varepsilon$ \\
\hline
\end{tabular}

Fayoum J. Agric. Res. \& Dev., Vol. 31, No.1, January, 2017 
$r$.

سادساً: إقتراح خطة عمل لبرنامج تدريبى لتأهيل شباب القرى للعمل فى الحرف البيئية الريفية

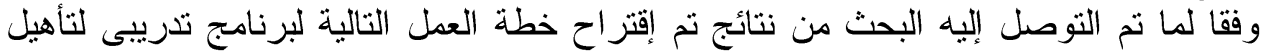

شباب الخريجين للعمل بالحرف البيئية الريفية.

إقتراح خطة عمل لبرنامج تدريبى لتأهيل شباب القرى للعمل في الحرف البيئية الريفية

\begin{tabular}{|c|c|c|c|c|c|c|c|}
\hline التدريب & التدريب & التدريبية & اللتدريب المقترح & بالتددريب & |الجمتهوف & الانشطة & الاهداف \\
\hline الإحتباج & على الأقلّ & |الدحاضر اتل & المتخصصة الذلك & من الجصاتذة & الجنباب من النين & 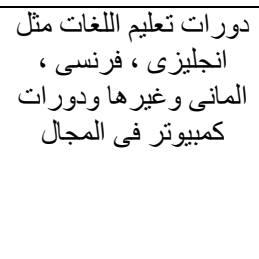 & 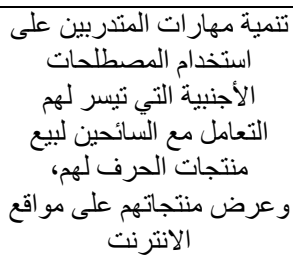 \\
\hline بصفة & 0 يوم & ايضاح زيار اترات & و في القرى الكعارض & فتخص مجال & |الجنباب من & عرض منتجات الحرف بـليب & تتمية مهار اتل المتدربين عرض منتجات \\
\hline الإحتباج & شهر & ايضاح عملى زيار & فى القرى & حرفيين مهرة & |الجنباب من |الجنين & 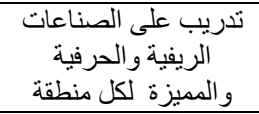 & تتمية مهار ات المتدربين على الحرفية \\
\hline الإحتباج & إسبو عان & عملى،زيار إناح & فى القنادق & فتخص تطوير اءين & |الجنباب من & التدريب على إنتاج حرف الثنانوى المزر من المنتى & 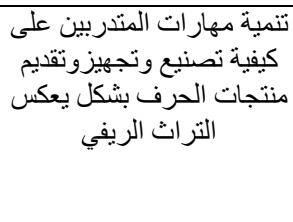 \\
\hline و مراة & إسبو عان & ايضاح عمل & فى القرى & خبر اء فى المجال & |الجنسبن من & تدريب على تطوير & 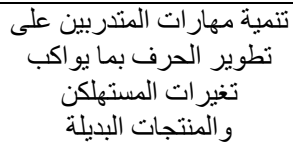 \\
\hline دورى & شهر & و ندوات، & فومى القرى & المتخراء & |الجنسبن من & المختلفة لتطوير منتجات الأشكال & زأيادية تطوفير الحربن بين \\
\hline و مراة & إسبو عان & إيضاح عملى زيار اتى & فى القرى & ونخصصين & |الجنسين من & منتجات التبف وطرف عرف ترضيئة البيئية & 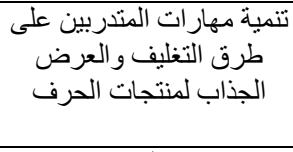 \\
\hline دورى & شهر & محاضر ات & الفنادق و القرى & خبر اء فى السياحة & | النباب من | الجنسين & التدريب على الإرشاد & 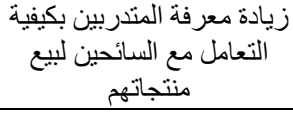 \\
\hline دورى & إسبو عان & زيارات، & فئى الفنادق & صناعة - معبر - معارضيم & |الشباب من & المعارض المتخ على إعدادة & زيادة معرفة المتدربين بكيفية \\
\hline
\end{tabular}

Fayoum J. Agric. Res. \& Dev., Vol. 31, No.1, January, 2017 


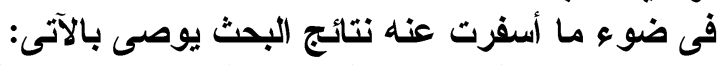

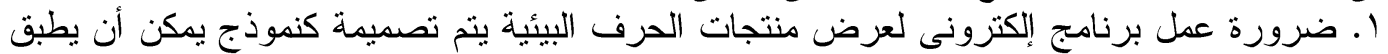

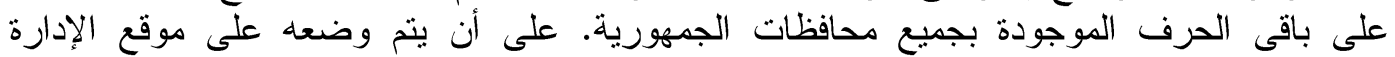

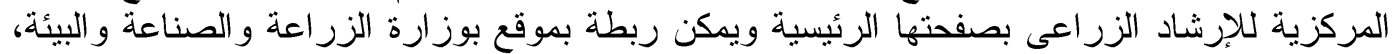

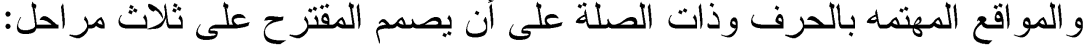

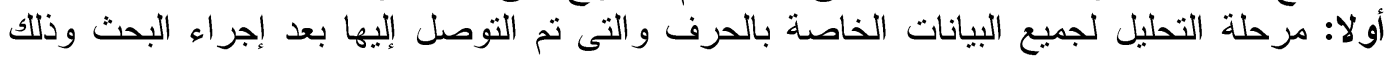

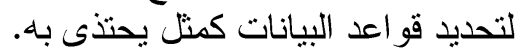

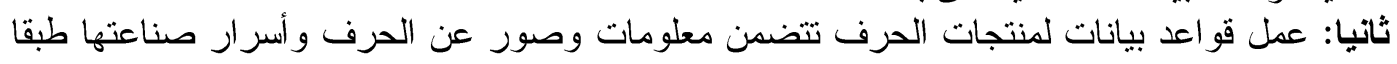

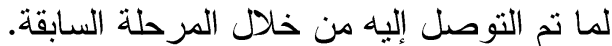

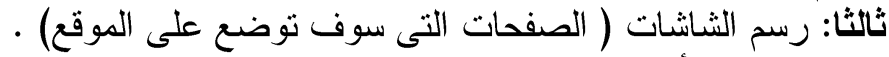

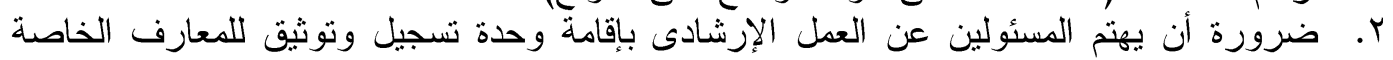

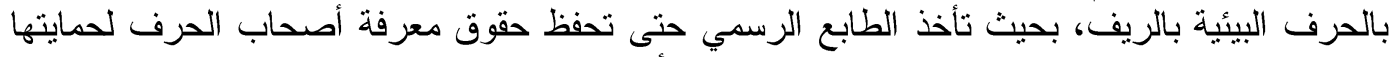

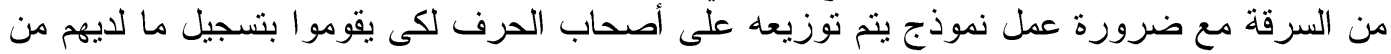

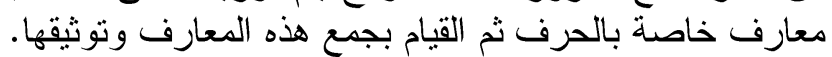

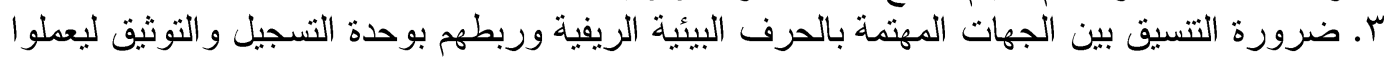

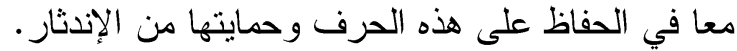

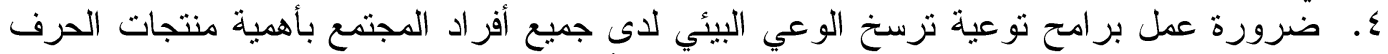

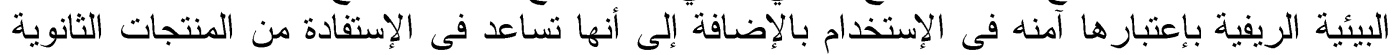

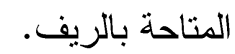
هـ ضرورة أن تهنم الجهات المعنية بإجر اء بحوث تشمل محافظات جمهورية مصر العربية ذات الصلة بالحرف البيئة بغرض توثينها و والحفاظ عليها وعمل خريطة رقميه لهصر تشمل تلك الحرف و الأفزاد و أماكن تو اجد أصحابها.

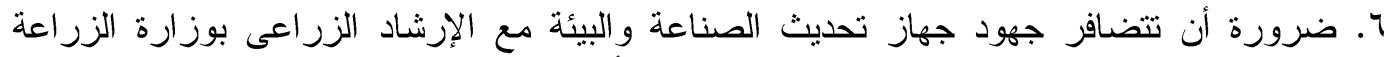

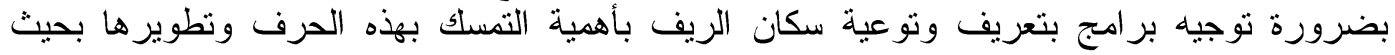

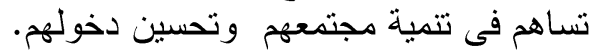

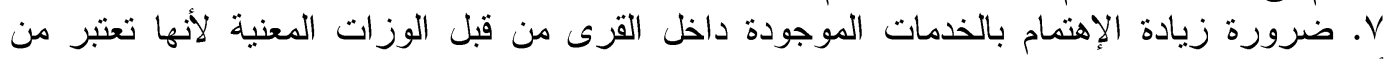

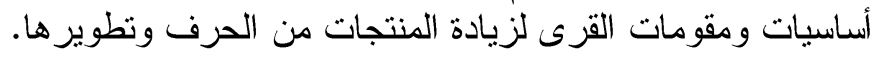
^. ضرورة التتسيق بين وزارة السياحة والإعلام للإِعلان و الترويج عن الحرف البناف البيأية الريفية الموجود

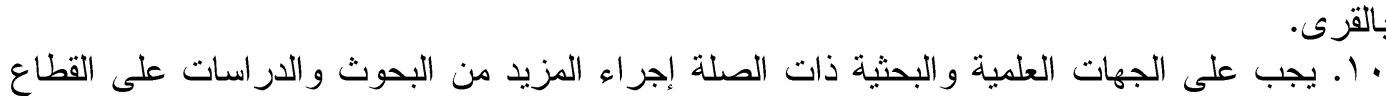

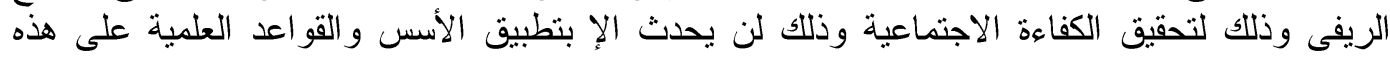

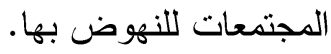

المر اجيع

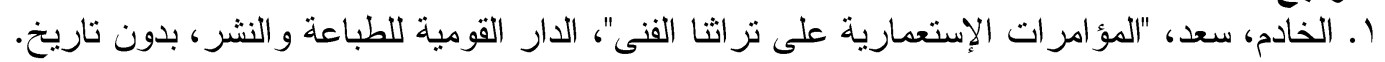

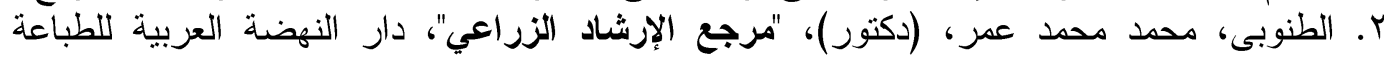

Fayoum J. Agric. Res. \& Dev., Vol. 31, No.1, January, 2017 


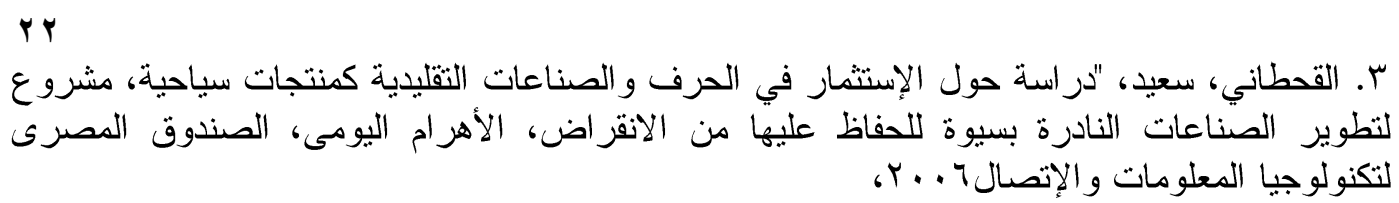

Available at: http://www.kenanaonline.net/page/3147:visited in:2/6/2014.

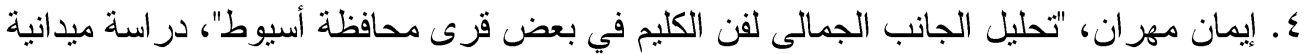

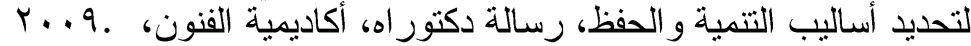

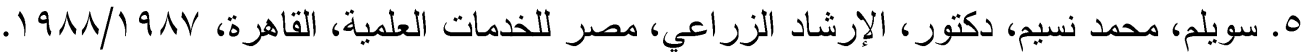

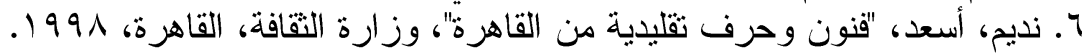

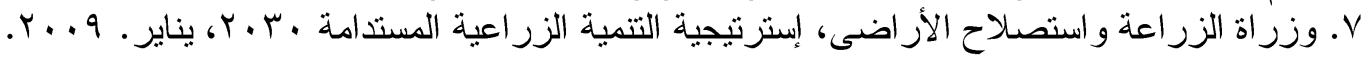

\title{
RURAL ENVIRONMENTAL CRAFTS SPREAD IN SOME VILLAGES OF EL FAYOUM GOVERNORATE AND THE WORKERS VIEWS ON ITS PROBLEMS AND THE SOLUTION
}

\section{Dr. Laila M. D. El-habaa}

Senior Researcher

Agricultural Eextension and Rural Development Research Institute

\begin{abstract}
The research aimed at identifying the private information rural environmental crafts spread in the research area,identifying its type, the most people workein it, the ways to transfer it to the sons how to learn the crafts, the development happened to the crafts, and why it happened. Also the research aimed at identifying te problems facing the warkers in there crafts and their suggestions to solve it, as well as their opinion on the role of agricultural extension to develop there crafts.

The research was conducted on a sample of 190 respondents, who works on there crafts, they were selected from the centers and villages depending onElakhbers people. Data were collected through personal interview by using pretested questionnaire during April 2015. Frequencie, percentages and numbers were used to present study data.

The most important results of this research are:

- The most important environmental crafts were Jerid (30\%) followed by handmade carpets (20\%).

- The transmission way the craft from parents to children, has been ranked first in learning children the craft to heredity $(44.7 \%)$, and learning the craft from experties of the craft $(22.6 \%)$.
\end{abstract}

Fayoum J. Agric. Res. \& Dev., Vol. 31, No.1, January, 2017 
- How to learn the person craft in the village, where the first class in how to learn people profession training in childhood by $49.5 \%$, and occupied the second place full of craft owners homeliness by $30.5 \%$.

- The inrelation extent of development of environmental crafts it was found that $78.4 \%$ to craft Jerid that the craft stayed as it is inherited and evolution was a simple multiple products, either craft of hand made carpets see respondents by $79.5 \%$ it's been more evolution in form and material, As for artifacts palm leaves craft has $59.5 \%$ of the respondents reported that the craft has evolved in multiple product, while respondents said mat sedge $92.1 \% \%$ that the craft stays as it is inherited, either for Palm leaf craft sees 85.3 percent of the respondents that craft as it is inherited.

- The most important problems that reduce the transmission of the cra from parents to children material revenue from the craft are few and non-permanent or fixed by $60.5 \%$, and the failure of the State to provide any support for raw materials increased by $75.8 \%$, and Few product's price because the trader collects the product from the village and then sell it for him at 86.8 .

- It was the most important suggestion Respondents to overcoming the problems with business and health insurance for owners of the crafts by $98.4 \%$.

- Than half of the respondents $(50.5 \%)$ agree to help agricultural extension in the field of activated environmental crafts, which related with the agricultural sector.

Fayoum J. Agric. Res. \& Dev., Vol. 31, No.1, January, 2017 